\title{
Development of Measurement System for Flow and Shape Using Array Ultrasonic Sensors
}

\author{
Munkhbat Batsaikhan, Zeliang Zhang, Hideharu Takahashi, Hiroshige Kikura \\ Department of Mechanical Engineering, Tokyo Institute of Technology, Tokyo, Japan \\ Email: batsaikhan.m.aa@m.titech.ac.jp
}

How to cite this paper: Batsaikhan, M., Zhang, Z.L., Takahashi, H. and Kikura, H. (2021) Development of Measurement System for Flow and Shape Using Array Ultrasonic Sensors. Journal of Flow Control, Measurement \& Visualization, 9, 45-72. https://doi.org/10.4236/jfcmv.2021.93004

Received: September 28, 2020

Accepted: July 24, 2021

Published: July 27, 2021

Copyright $\odot 2021$ by author(s) and Scientific Research Publishing Inc. This work is licensed under the Creative Commons Attribution International License (CC BY 4.0).

http://creativecommons.org/licenses/by/4.0/ (c) (i) Open Access

\begin{abstract}
In Fukushima Daiichi Nuclear Power Plant (FDNPP) accident, the fuel debris formed in the Reactor Pressure Vessel (RPV) and Primary Containment Vessel (PCV) at Unit 1 - 3. To accelerate and decide further decommissioning steps of the FDNPP, it is crucial to obtain realistic information of the debris and localize contaminated water leakage from PCV. Due to high radiation and dark environment inside the PCV, investigating instruments and techniques should necessarily to meet specification of radiation resistance, waterproofness, dust resistance and so on. This study focuses on development of ultrasonic measurement system using a couple of sectorial array sensors to localize contaminated water leakage and visualize shape of object that representing fuel debris, simultaneously. In this study, Total Focusing Method (TFM) and Ultrasonic Velocity Profiler (UVP) methods are considered to visualize object shape and flow pattern around it, respectively. To demonstrate applicability and reliability of developed measurement system with sectorial array sensors, a mock-up experiment result of simulated water leakage and fuel debris shape were discussed in this paper.
\end{abstract}

\section{Keywords}

Reactor Decommissioning, Sectorial Array Sensors, Total Focusing Method (TFM), Ultrasound, Ultrasonic Velocity Profiler (UVP), Vector Flow Mapping

\section{Introduction}

Severe accident at FDNPP occurred after 9.0 magnitude earthquake and a huge tsunami that struck the Tohoku region of Japan. The cold-shutdown condition of the reactors announced by the end of 2011 and the Japanese Government has drawn mid-and-long term roadmap (hereafter referred as the roadmap) towards 
decommissioning. According to the roadmap, the debris removal from the Unit-2 is scheduled to start within 2021 [1]. However, the fuel debris distribution is still unclear. Submersion method is considering as a basic and possible method for fuel debris retrieval from PCV of FDNPP [2]. Because the fuel debris generates heat that caused by radioactive decay, the submersion method allows to keep cooling the debris. Moreover, the water can be shield from radiation during fuel removal. Due to strong earthquake and tsunami, the PCV had damaged and there is water leakage from PCV's wall [3]. To retrieve the fuel debris under submersion method, these water leakage and generation of contaminated water must be stopped. However, the leakage may be presented near fuel debris, under turbid water and at narrow places [4]. Due to high radiation environment inside damaged reactor buildings, human access to reactor building is impossible. Therefore, depending on the environment and condition of each units, internal investigation of the PCV for Unit 1 - 3 of FDNPP has performed by remote measurement techniques such as robots that installed camera [5] [6] [7]. Main target of those inspections is to obtain debris and water leakage information. Although the camera is direct observation way to see inside of PCV, the camera visibility reduces and noise caused by high radiation dose [8] [9] [10]. To respond to the situation inside the RPV and the bottom of the PCV where fuel debris is predominantly present, investigating device should necessarily meet specification of radiation resistance, waterproofness, dust resistance and so on [4].

In the present study, ultrasonic measurement is considered as a candidate method to localize contaminated water leakage and debris inside the PCV. Because the water leakage can be predicted by $2 \mathrm{D}$ velocity vector measurement based on its direction and magnitude. Moreover, ultrasound can be used to visualize objects under non-transparent medium such as under turbid water in the PCV. An ultrasonic measurement system used to visualize a reactor core that damaged during severe accident of Unit 2 in Three Mile Island (TMI), US [11]. Therefore, present study focuses on the Ultrasonic Velocity Profiler (UVP) and Total Focusing Method (TFM) methods to measure 2D vector flow field and shape of object that representing fuel debris, respectively. The water flow passing objects encompass a variety of fluid mechanics phenomena. The character of the flow field strongly depends on the shape and size of the object. Even the simple shaped objects, like a round, produce rather complex flows [12]. Therefore, simultaneous visualization of the flow and object shape is crucial for internal inspection of PCV where turbid water is circulating. In Section 2 of this paper, basic principle of measurement techniques for $2 \mathrm{D}$ velocity vector measurement using the UVP and object shape visualization using the TFM methods will be described. Section 3 will describe design of ultrasonic array sensors and its properties. The performance of sectorial array sensors has tested using smooth and rough objects under with and without flow conditions. The measurement results of these experiments will be described in Sections 4 and 5 respectively. Finally, summary of main findings of present study will be given in Section 6 . 


\section{Principle of Measurement Techniques for Flow and Shape}

\subsection{Basic Principle of 2D Flow Field Measurement by UVP Method}

This study focuses on time averaged 2D velocity field measurement by the UVP method. The UVP method is based on the pulsed echography and it can measure instantaneous velocity profile of fluid along ultrasound beam by analyzing echo signals that reflected from seeding particles [13]. Basic measurement principle of UVP is illustrated using a simple pipe flow in Figure 1. In UVP measurement, particles that nearly equal density of fluid are used as an ultrasound reflectors. A pulsed ultrasound waves are emitted from a sensor with a basic frequency $\left(f_{0}\right)$ along measurement line with incident angle $(\theta)$. Then reflected echo signals from particles are detected at same sensor. The pulsed ultrasound has a spatial resolution as illustrated by yellow rectangles in Figure 1. According to Equation (1), the distance between each measurement volume and sensor surface is estimated based on the time interval between emission and reception of the signals. The reflected echo signal contains Doppler shift frequency $\left(f_{d}\right)$ that containing velocity information of moving particles. Therefore the velocity profile along measurement line is reconstructed by Equation (2).

$$
\begin{gathered}
x=\frac{c T}{2} \\
V(x)=\frac{c f_{D}}{2 f_{0} \sin (\theta)}
\end{gathered}
$$

Main part of the UVP method is to estimate Doppler shift frequency. It is difficult to estimate Doppler shift frequency from an echo signal because it is much smaller than the basic frequency. Therefore, multiple emissions are used to measure velocity profile, at least 2 and typically 128 . Figure 2 is demonstrated a block diagram of the signal processing part of the UVP. Doppler shift frequency is estimated by autocorrelation method [14] in this work. According to Figure 2, a pulser and receiver is used to emit and receive the ultrasonic waves through same sensor. The received echo signals contains both carrier and shifted signals. The quadrature detection where echo signals are multiplied by sine and cosine components is applied to separate signals. Then low pass filter is used to eliminate the carrier waves. The complex envelope signal $z(t)$ after the low pass filter is explained [3] as

$$
z(t)=I(t)+j Q(t)
$$

where, $I(t)$ and $Q(t)$ are the in-phase signal and the quadrature phase signal with the received signal, respectively. The autocorrelation function $R f$ is expressed as

$$
R f=\left(T_{P R F}, t\right)=\int z(t) \times z^{*}\left(t-T_{P R F}\right) \mathrm{d} t=R_{x}\left(T_{P R F}, t\right)+j R_{y}\left(T_{P R F}, t\right)
$$

where, $T_{P R F}$ is the time interval of the pulse emission, $z^{*}$ is the conjugate complex signal of $z(t) . R_{x}$ and $R_{y}$ are the real and imaginary part of $R f$, respectively. The phase shift between consecutive echo signals is expressed as 


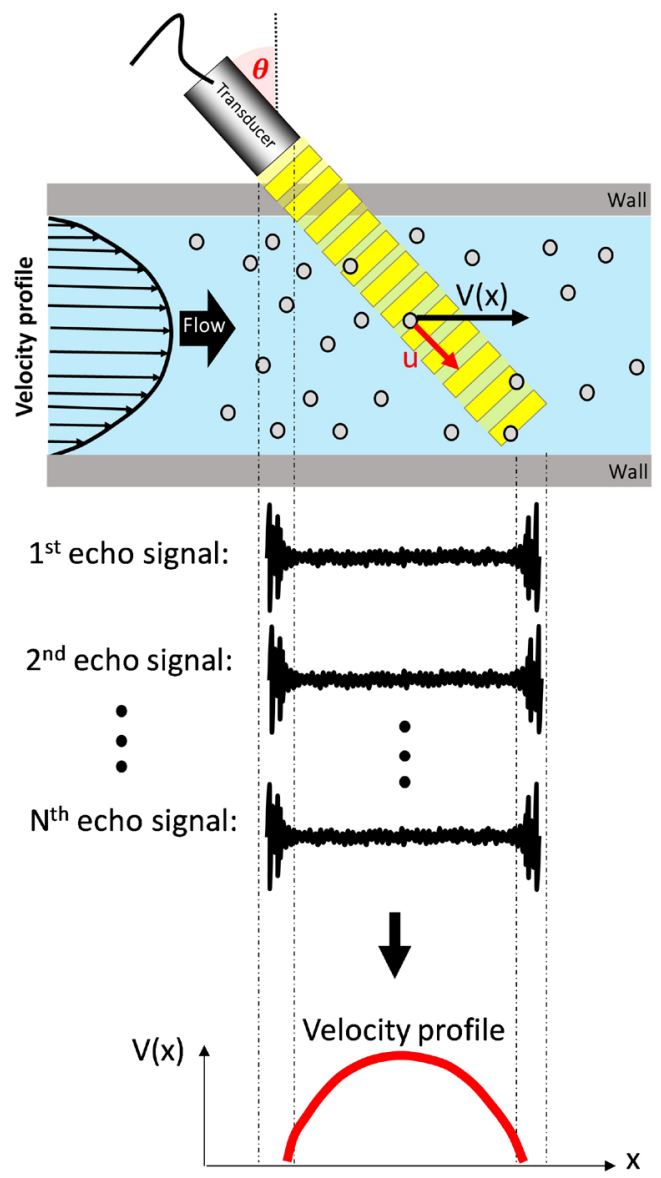

Figure 1. Simplified illustration of UVP measurement, echo signals and reconstruction of velocity profile by pulse repetition method.

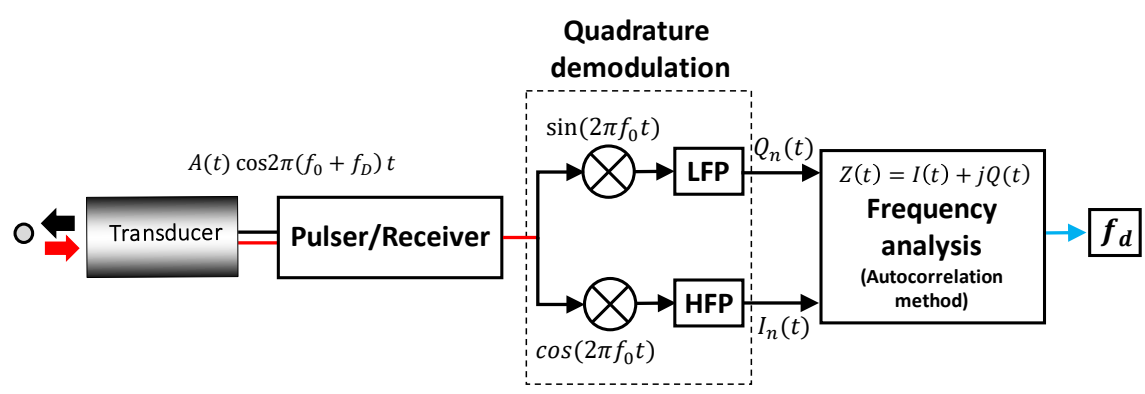

Figure 2. Block diagram of Doppler signal estimation of UVP system.

$$
\varphi\left(T_{P R F}, t\right)=\tan ^{-1} \frac{R_{x}\left(T_{P R F}, t\right)}{R_{y}\left(T_{P R F}, t\right)}
$$

Doppler shift frequency is obtained as follows

$$
f_{D}=\frac{1}{2 \pi T_{P R F}} \tan ^{-1} \frac{R_{x}\left(T_{P R F}, t\right)}{R_{y}\left(T_{P R F}, t\right)}
$$

Eventually, a velocity profile can be obtained by analyzing the echo signals to derive instantaneous frequencies at each instant. 
Originally the UVP method is proposed for one dimensional velocity profile measurement. Main purpose of this work is to introduce a principle of two-dimensional velocity field measurement based on the UVP method. There are several ways to measure $2 \mathrm{D}$ velocity field by UVP method. For instance, one transmitting and two/three-receivers configuration of ultrasonic sensors are an option for 2D/3D instantaneous vector measurement [15]. Moreover, phased array is an advanced tool for multi-dimensional flow measurement technique despite precise time delay controlling to steering beam and its measurement angle limitation due to grating lobes. Combining Doppler measurements taken along multiple intersecting ultrasound beams is one of approach to obtaining $2 \mathrm{D}$ velocity vector field. It is also referred as cross-beam technique in medical field [16]. In addition, single [17] and multiple ultrasonic sensors [18], such techniques is applied for 2D mapping of liquid metal flow. Based on this approach using a couple of sectorial array sensors, a validation experiment had performed comparing with high-speed camera measurement technique in our previous studies [19] [20]. The ultrasonic sensor composed with two or more single-element is first step in 2D velocity measurement as illustrated in Figure 3.

In cross-beam technique, two velocity components, $u_{1}$ and $u_{2}$, at one spatial point measured by sensor-1(TX-1) and sensor-2(TX-2) are used to form a velocity vector, $V$. Ignoring the influence of ultrasound beam width, only the centerline of ultrasound beam considered in UVP to obtain an intersection points $d_{1}$ and $d_{2}$ [13]. The $u_{1}$ and $u_{2}$ are velocity components that measured directly by individual sensors. Let's assume there are two measurement lines, illustrated in Figure 3, defined as

Measurement line 1:

$$
\begin{aligned}
& x_{1}=x_{T \times 1}+d_{1} \cos \theta_{1} . \\
& y_{1}=y_{T \times 1}+d_{1} \sin \theta_{1} .
\end{aligned}
$$

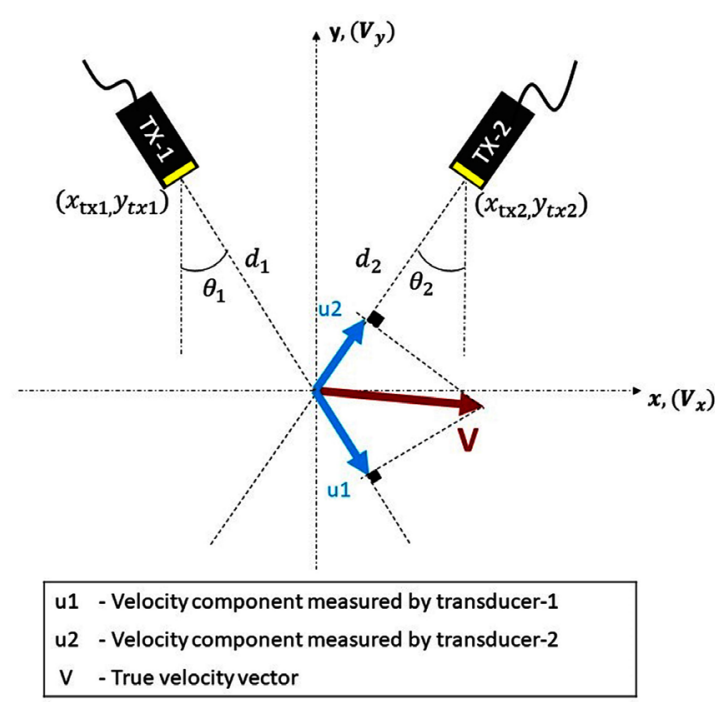

Figure 3. 2D vector reconstruction using single-element and two sensors. 
Measurement line 2:

$$
\begin{aligned}
& x_{2}=x_{T \times 2}+d_{2} \cos \theta_{2} . \\
& y_{2}=y_{T \times 2}+d_{2} \sin \theta_{2} .
\end{aligned}
$$

where, $x_{T \times 1}, x_{T \times 2}, y_{T \times 1}, y_{T \times 2}$ are coordinate of sensors. $\theta_{1}$ and $\theta_{2}$ are incident angle of sensors relative to flow. The $d_{1}$ and $d_{2}$ are distance from sensor to intersection point of these two lines are expressed as Equation (11) and Equation (12).

$$
\begin{aligned}
& d_{1}=\frac{\left(x_{T \times 1}-x_{T \times 2}\right) \cdot \sin \theta_{2}-\left(y_{T \times 1}-y_{T \times 2}\right) \cdot \cos \theta_{2}}{\sin \left(\theta_{1}-\theta_{2}\right)} . \\
& d_{2}=\frac{\left(x_{T \times 1}-x_{T \times 2}\right) \cdot \sin \theta_{1}+\left(y_{T \times 1}-y_{T \times 2}\right) \cdot \cos \theta_{1}}{\sin \left(\theta_{1}-\theta_{2}\right)} .
\end{aligned}
$$

The distance are divided into the channel width $(w)$ to determine what measurement channels $(C h)$ are crossing with each other.

$$
\begin{gathered}
C h_{1}=\frac{d_{1}}{w_{i, 1}} . \\
C h_{2}=\frac{d_{2}}{w_{i, 2}} .
\end{gathered}
$$

Then, velocity components $u_{1}$ and $u_{2}$ at $C h_{1}$ and $C h_{2}$ channels that measured by TX-1 and TX-2 are extracted, respectively. Finally, the velocity $V_{X}$ and $V_{Y}$ are calculated according to Equation (15) and Equation (16).

$$
\begin{gathered}
V_{x}=\frac{u_{1}+V_{y} \cos \theta_{1}}{\cos \theta_{1}} . \\
V_{y}=\frac{u_{1} \cos \theta_{1}+u_{2} \cos \theta_{1}}{-\sin \theta_{1} \cos \theta_{2}-\sin \theta_{2} \cos \theta_{1}} .
\end{gathered}
$$

The spatial and temporal resolution of the UVP, in case of one-dimensional velocity profile measurement, are defined by Equation (17) and Equation (18), respectively.

$$
\Delta x=\frac{n \lambda}{2}
$$

where, $\Delta x$ is spatial resolution, $n$ is number of cycle per pulse, $\lambda$ is wavelength.

$$
\Delta t=\frac{N_{\text {rep }}}{P R F} .
$$

where, $\Delta t$ is temporal resolution, $N_{\text {rep }}$ is number of repetitions per profile and $P R F$ is pulse repetition frequency. In the cross-beam measurement technique for $2 \mathrm{D}$ velocity vector field, it is desirable to have multi sensors because number of velocity vectors proportional to the number of intersection points of measurement lines. To obtain 2D velocity vector field, a careful settling or handling of sensors should be considered when multi and single-element sensors are used. Array sensors that consists with multi elements are appropriate tool comparing 
with single-element and multi sensors for $2 \mathrm{D}$ flow pattern because the settling error and measurement time can be reduced when array sensors are used as illustrated in Figure 4. Therefore, sectorial shaped ultrasonic array sensors have designed in the present study. A couple of sectorial array sensors have advantages comparing with single-element multi sensors and linear array sensors. For instance, measurement area as indicated by orange color in Figure 4 is able to change depends on the distance between two sensors while measurement area in linear array sensors is constant by changing distance between two sensors. The spatial resolution of $2 \mathrm{D}$ velocity vector field by sectorial array sensors is defined by the distance between intersection point of measurement lines along vertical and horizontal directions. On the other hand, the temporal resolution of $2 \mathrm{D}$ velocity field measurement is described according to Equation (19).

$$
\Delta t_{2 D}=\frac{N_{\text {rep }}}{P R F} \cdot N \cdot t_{\text {switch }} .
$$

where, $N$ is number of elements in array sensors, $t_{\text {switch }}$ is switching time between elements in array sensors.

\subsection{Basic Principle of Ultrasonic Imaging by TFM Method}

Application of ultrasonic imaging is common in the medical and non-destructive testing because of its instant result, radiation-free and non-intrusive properties. Wide variety of ultrasonic imaging algorithms have developed in these fields. This study focuses on Total Focusing Method (TFM) as a post-processing algorithm to visualize object shape that representing fuel debris. The TFM algorithm provides a best image resolution than any other standard imaging technique [21]. In this method, all possible pairs of transmitting $(N)$ and receiving $(N)$ time domain signals, $A_{i j}(t)$, collected by the array sensor. This set of data is referred as the Full Matrix Capture. To reconstruct image, the TFM method uses timedomain signals $S_{i j}(t)$ that obtained by the Hilbert's transform of the raw signals, $A_{i j}(t)$ :

$$
S_{i j}(t)=A_{i j}(t)+j h\left[A_{i j}(t)\right] .
$$

Let's considering a point $P(x, z)$ in the imaging plane as illustrated in Figure 5. In the Figure 5, the green arrow is representing emitting wave from array sensor-1 and reflected wave is illustrated by blue arrow which detected by array sensor-2. The intensity $P(x, z)$ at each imaging point is calculated by Equation (21).

$$
P(x, z)=\sum_{i=1}^{N} \sum_{j=1}^{N} D_{i} D_{j} S_{i j}\left(t_{i j}=t_{i}+t_{j}\right) .
$$

By assuming the medium under test is homogeneous and isotropic, the sound velocity is supposed to be constant. Therefore, the distance between transmitter and receiver calculates by Equation (22).

$$
t_{i j}=\frac{\sqrt{\left(x-x_{i}\right)^{2}+\left(z-z_{i}\right)^{2}}+\sqrt{\left(x-x_{j}\right)^{2}+\left(z-z_{j}\right)^{2}}}{c} .
$$



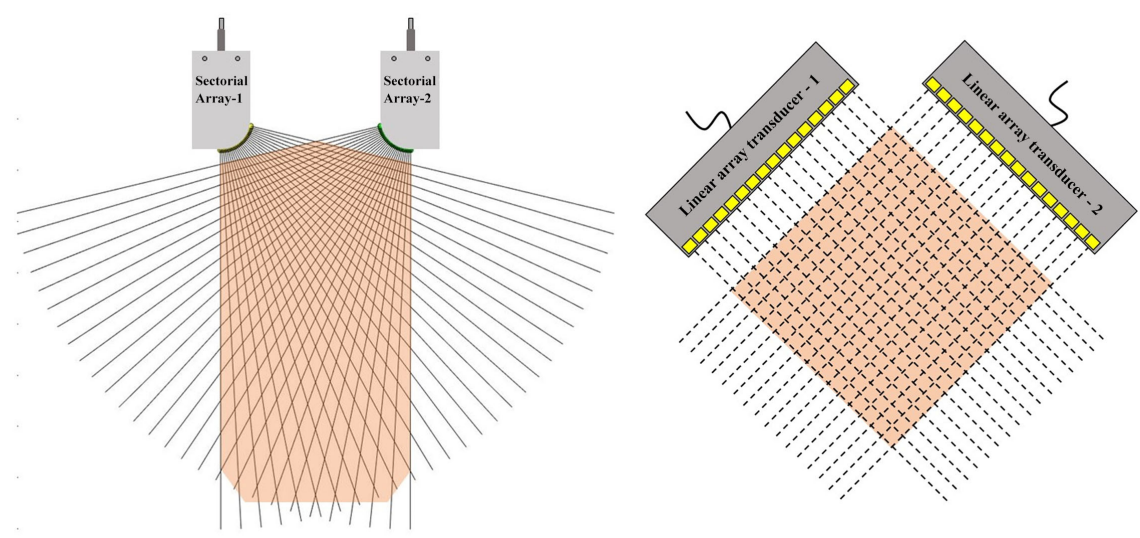

Figure 4. 2D velocity field measurement using a couple of sectorial and linear array sensors.

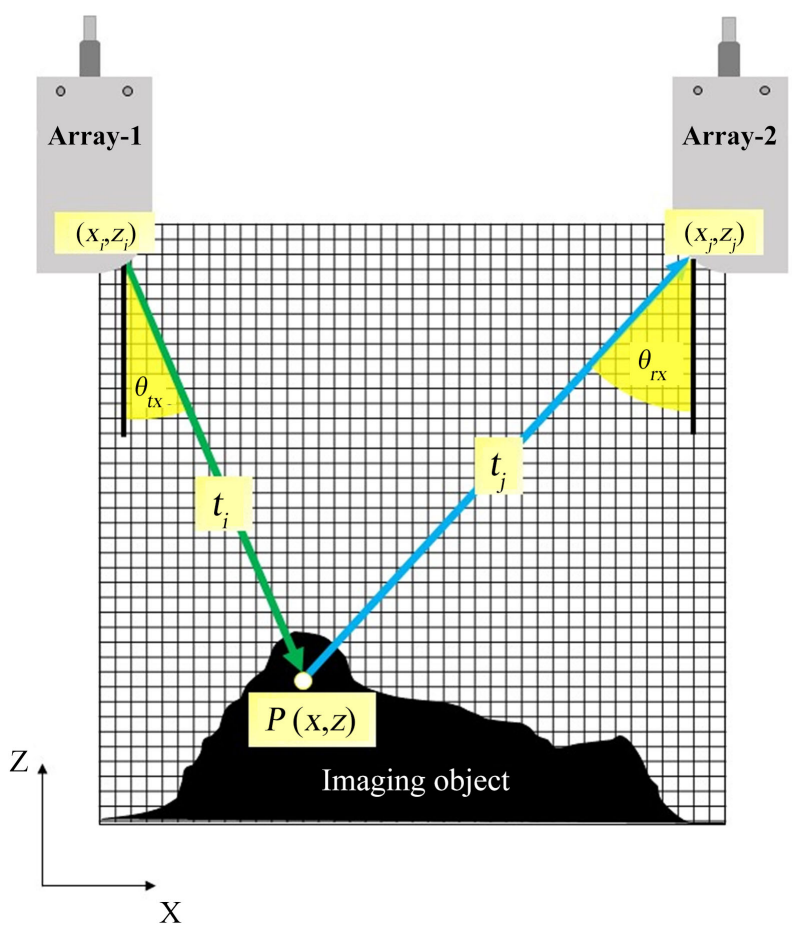

Figure 5. Shape measurement by a couple of sectorial array sensors using TFM method.

where, $x_{i j}, z_{i j}$ are coordinates of transmitting and receiving element in the array sensor, respectively. In TFM algorithm as a weighting factor, the directivity function of transmitting and receiving elements in two-dimensional model assumed as following Equations [21].

$$
\begin{aligned}
D_{i} & =\operatorname{sinc}\left(\frac{\sin \theta_{t x} \pi a}{\lambda}\right) . \\
D_{j} & =\operatorname{sinc}\left(\frac{\sin \theta_{r x} \pi a}{\lambda}\right) .
\end{aligned}
$$

where, $a$ is width of element in sectorial array sensor. 


\section{Design of Sectorial Array Sensors}

The specification of sectorial array sensors are showed in Figure 6. There are 256 piezoelectric elements in two sensors and each sectorial array sensor consists with 128 piezoelectric elements. The element width and height of piezoelectric are $0.1 \mathrm{~mm}$ and $5 \mathrm{~mm}$, respectively. The angle between two neighboring elements in the array sensor is 0.7 degree. Curvature of array sensor where elements presents is $12.2 \mathrm{~mm}$.

To assess performance of sectorial array sensors, sound pressure distribution is carried out by needle hydrophone under water. Figure 7 shows experimental the set-up for the sound pressure distribution. It consists with automatic 3D stage which is installed on top of the water tank, a stage controller (Sigma Kiko Co., Ltd.), a pulser \& receiver (600C, P/R, Japan Probe Co.Ltd.) and a PC. The $3 \mathrm{D}$ stage is controlled by LabVIEW software in the PC. The sectorial array sensor is connected to the Multiplexer (MUX) and Pulser/Receiver (P/R, 600C, Japan Probe Co.Ltd.) which generates a pulse. The experiment were performed

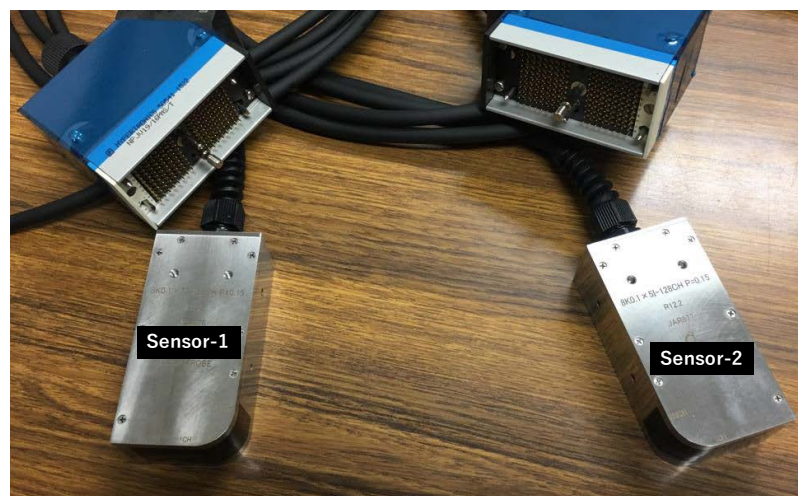

(a)

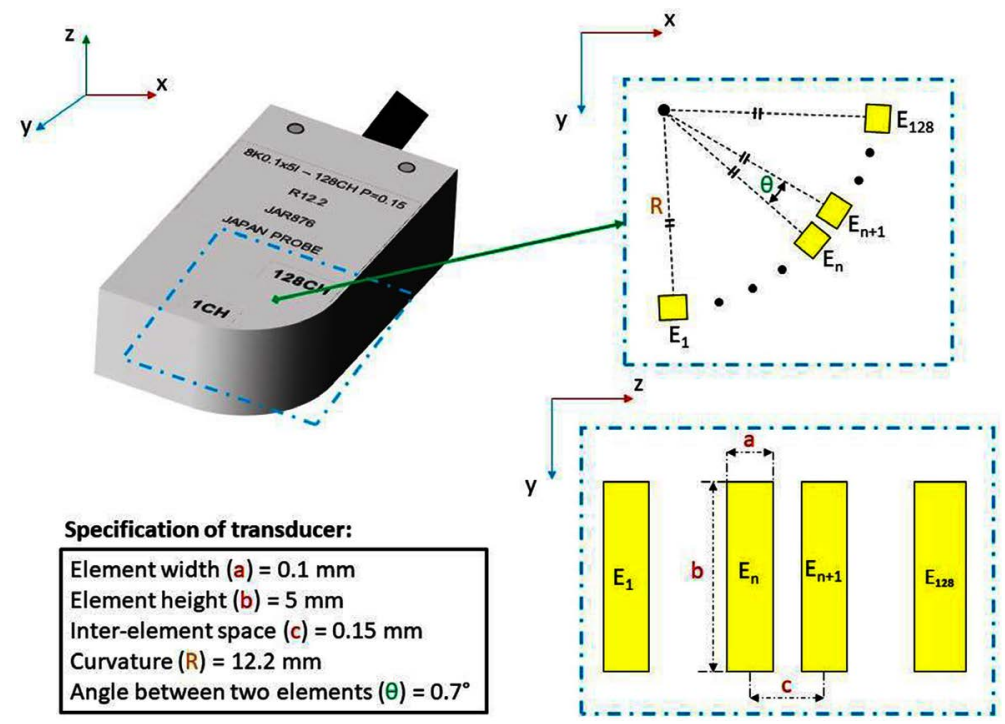

(b)

Figure 6. Specification of sectorial array sensors (a) Photo of sectorial arrays, (b) Detailed specification. 


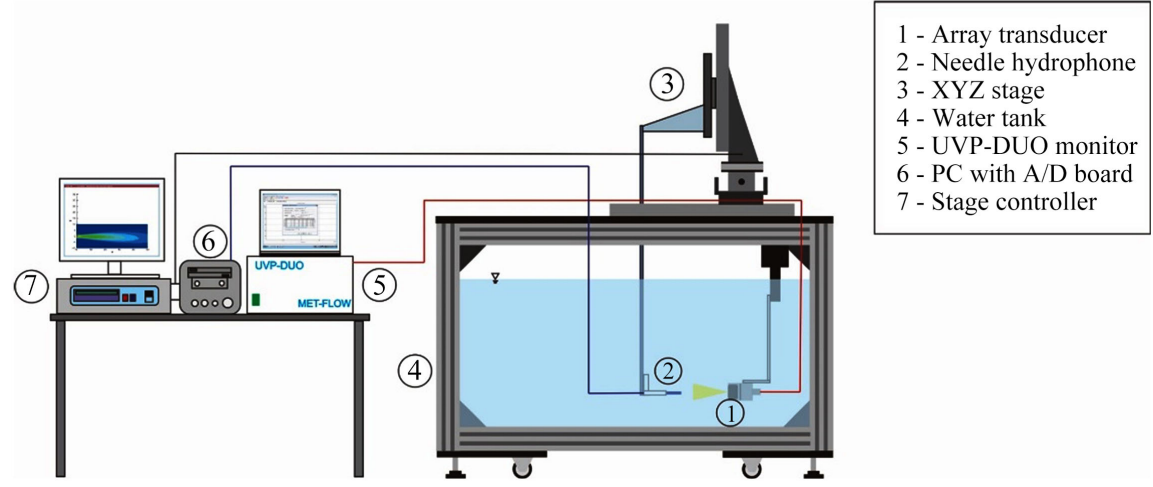

Figure 7. Measurement system for sound pressure distribution.

under stagnant water and water temperature was $17^{\circ} \mathrm{C}$. The needle hydrophone was traversed by the $3 \mathrm{D}$ stage to measure the ultrasonic signals according to preditermined grid. The resolution of the grid was $2 \mathrm{~mm} \times 2 \mathrm{~mm}$ along both lateral and axial directions The peak-to-peak between the maximum and minimum of the received signal was considered as the ultrasound pressure at the each measurement points. The measured values were used to calculated sound pressure level (SPL) according to Equation (25).

$$
S P L=20 \log _{10}\left(\frac{P}{P_{0}}\right) .
$$

where, $S P L$ - sound pressure level in decibel $[\mathrm{dB}], P$-sound pressure at spatial point, $P_{0}$-reference sound pressure.

The sound pressure distribution of element No.64 in array sensor-1 is illustrated in Figure 8. In the Figure 8, $\mathrm{x}$ - and y-axis are representing axial and lateral directions, respectively. The legend is showing SPL at each spatial location of measurement. The SPL decreases (see Figure 9(a)) with increasing axial distance and variation of $S P L$ was measured within $-20 \mathrm{~dB}$ until $195 \mathrm{~mm}$. To assess beam width along lateral direction, Full Width at Half Maximum (FWHM) is calculated at center along axial positions. An example of the FWHM calculation at axial direction of $50 \mathrm{~mm}$ is showed in Figure 9(b) and Figure 9(c) shows the FWHM versus different axial positions.

\section{Shape Measurement by Sectorial Array Sensor (without Flow)}

\subsection{Test on Smooth Surface}

To demonstrate imaging accuracy of the sectorial array sensors, different size of metal rectangle objects had measured in big acrylic tank that is used for sound pressure distribution experiment. The measurements were performed in stagnant water. The size of rectangle objects were $1 \mathrm{~mm}, 3 \mathrm{~mm}, 5 \mathrm{~mm}, 15 \mathrm{~mm}, 25$ $\mathrm{mm}$ and $50 \mathrm{~mm}$. The experimental set-up is illustrated in Figure 10. In this experiment, distance between the sectorial array and rectangles objects were $d=50$ $\mathrm{mm}$ and $d=100 \mathrm{~mm}$. The measurement condition is listed in Table 1 . 


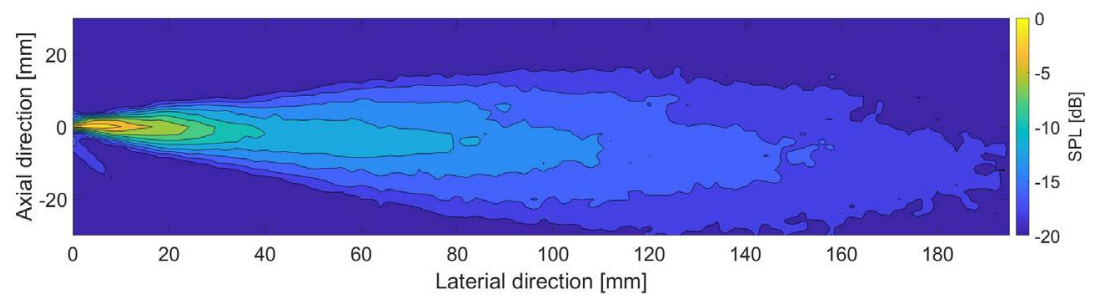

Figure 8. An example of sound pressure distribution of element No.64 in sensor-1.

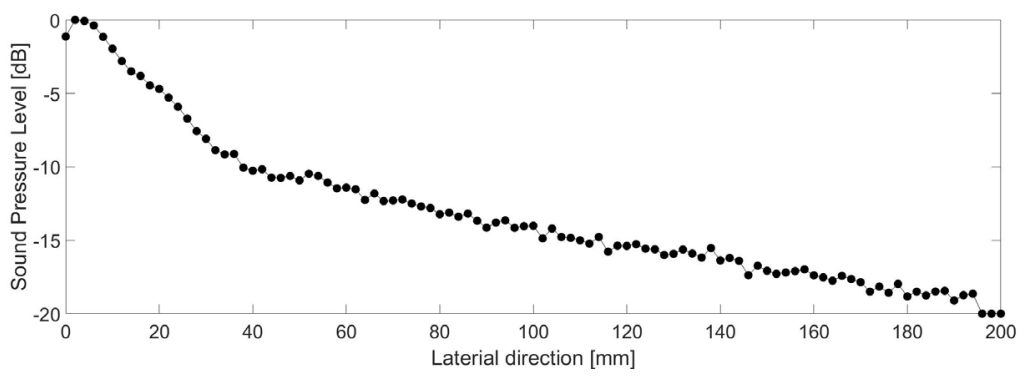

(a)

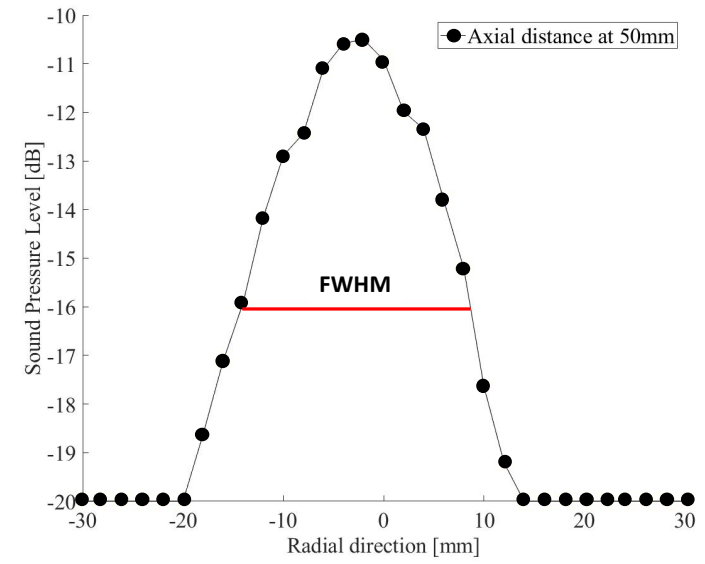

(b)

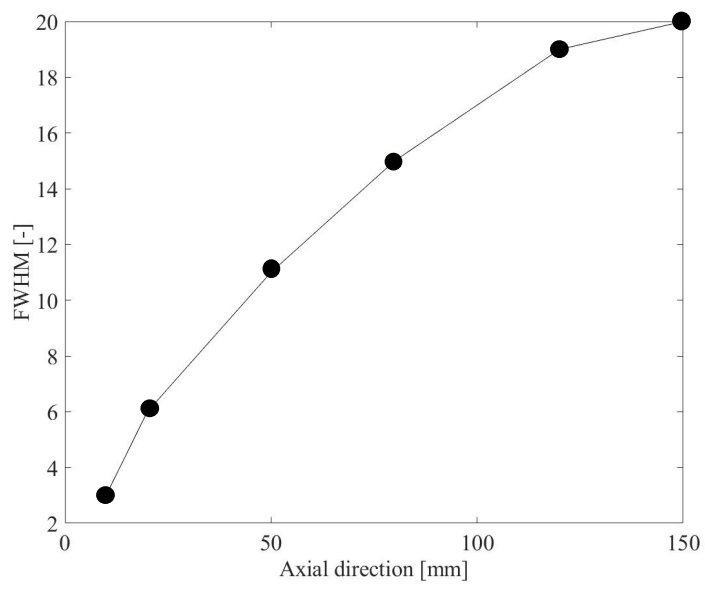

(c)

Figure 9. (a) Sound pressure level at the centerline (lateral direction $=0 \mathrm{~mm}$ ) along axial direction, (b) An example of FWHM calculation (axial distance $=50$ $\mathrm{mm}$ ) and (c) FWHM versus axial distance. 


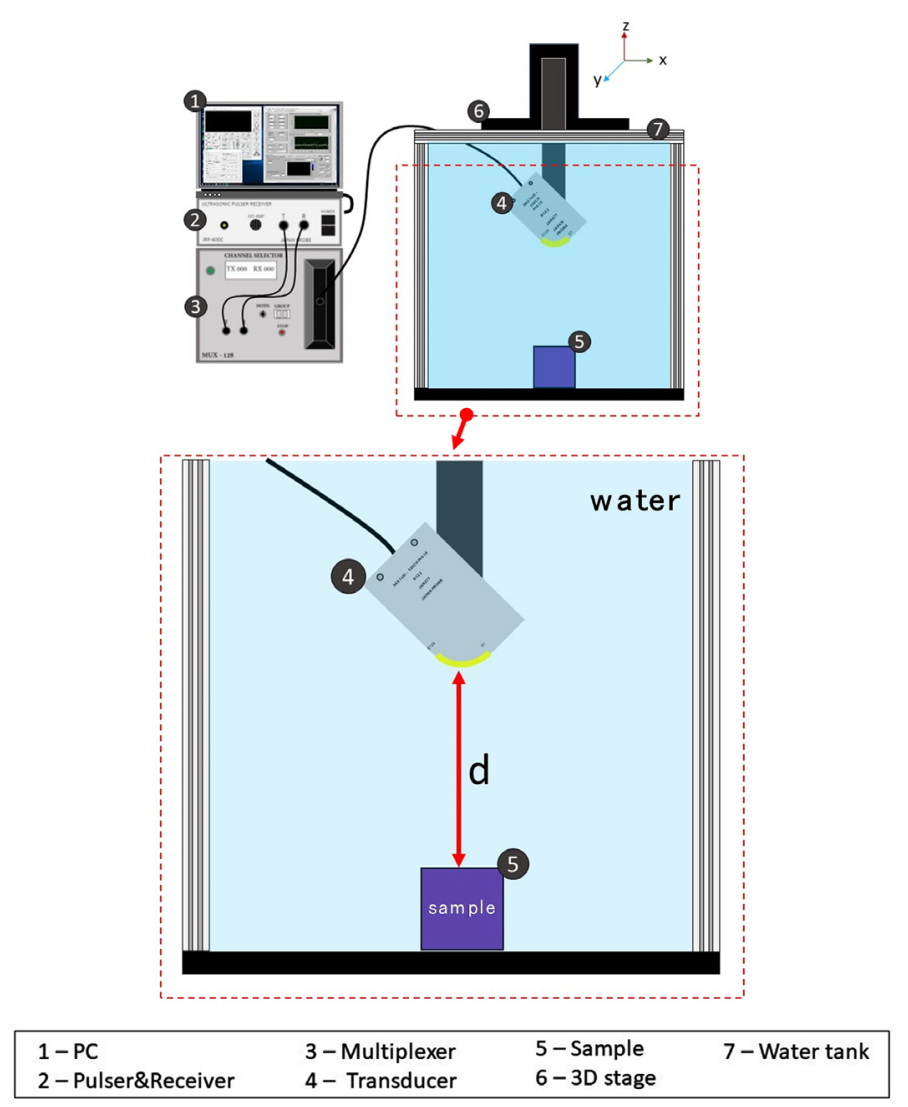

Figure 10. Experimental set-up for accuracy measurement.

Table 1. Measurement parameters.

\begin{tabular}{ccc}
\hline Parameters & Values & Units \\
\hline Sound speed & 1479 & {$[\mathrm{~m} / \mathrm{s}]$} \\
Basic frequency & 8 & {$[\mathrm{MHz}]$} \\
Number of cycles & 8 & {$[-]$} \\
Sampling rate & 20 & {$[\mathrm{MHz}]$} \\
Applied voltage & 120 & {$[\mathrm{~V}]$} \\
Gain value & 30 & {$[\mathrm{~dB}]$} \\
\hline
\end{tabular}

In data acquisition for shape visualization, totally, $128 \times 128$ time domain signals have collected and it used to reconstruct image of object by TFM method. Post processing is performed by MATLAB algorithm. An example of measurement results of $50 \times 50 \mathrm{~mm}$ rectangle at different axial distances are showed in Figure 11. According to measurement result in Figure 11, the top surface of rectangle objects and bottom wall of tank are visualized while there are some parabolic hyperbola artifacts are comes out at the edge of rectangle objects. The reason of hyperbola artefact is that emitted ultrasound beam from sensor has a finite beam width, the object illuminated for a finite length of the scanning axis. The artifact was strong when distance between sensor and object 
is close (see Figure 11) while the parabolic hyperbola artifact was decreasing when the axial distance increases. Figure 12 shows measurement results of six different size of rectangle objects. The bigger size rectangles such as $25 \mathrm{~mm}$ and $50 \mathrm{~mm}$ are accurately measured and the measurement error was less than $10 \%$. On the other hand, smaller size of rectangles such as $1 \mathrm{~mm}, 3 \mathrm{~mm}$ and $5 \mathrm{~mm}$ have larger error but less than $30 \%$.

\subsection{Test on Rough Surface}

To evaluate performance of sectorial array sensor on irregular shaped object that representing fuel debris have tested. The dimension of debris was the length of $80 \mathrm{~mm}$ (Y direction), width of $70 \mathrm{~mm}$ (X direction) and height of $50 \mathrm{~mm}$ ( $\mathrm{Z}$ direction). Photo of object is showed in Figure 14. Since the object is irregular, the

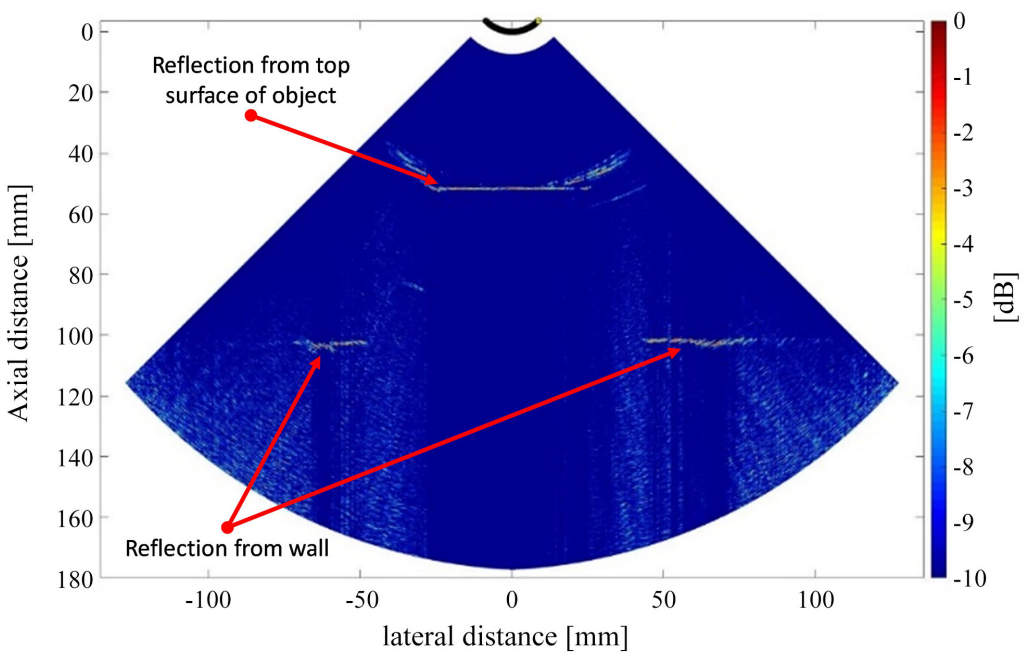

(a)

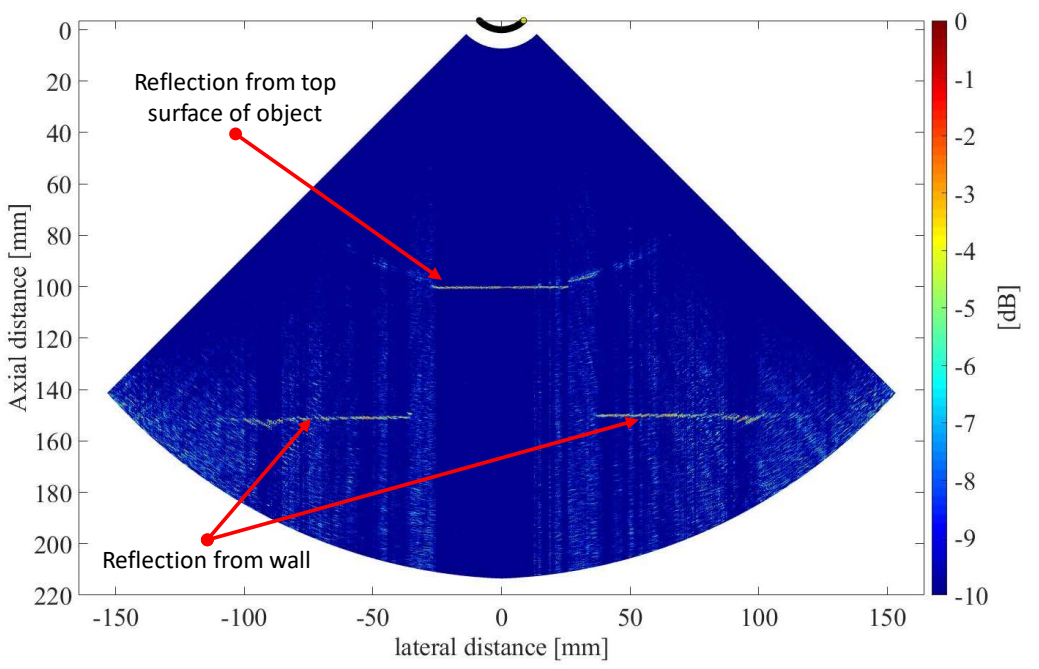

(b)

Figure 11. Measurement result of rectangle object (a) at $50 \mathrm{~mm}$ and (b) at 100 $\mathrm{mm}$. (a) Measurement result. $\mathrm{d}=50 \mathrm{~mm}$. (b) Measurement result. $\mathrm{d}=100$ $\mathrm{mm}$. 


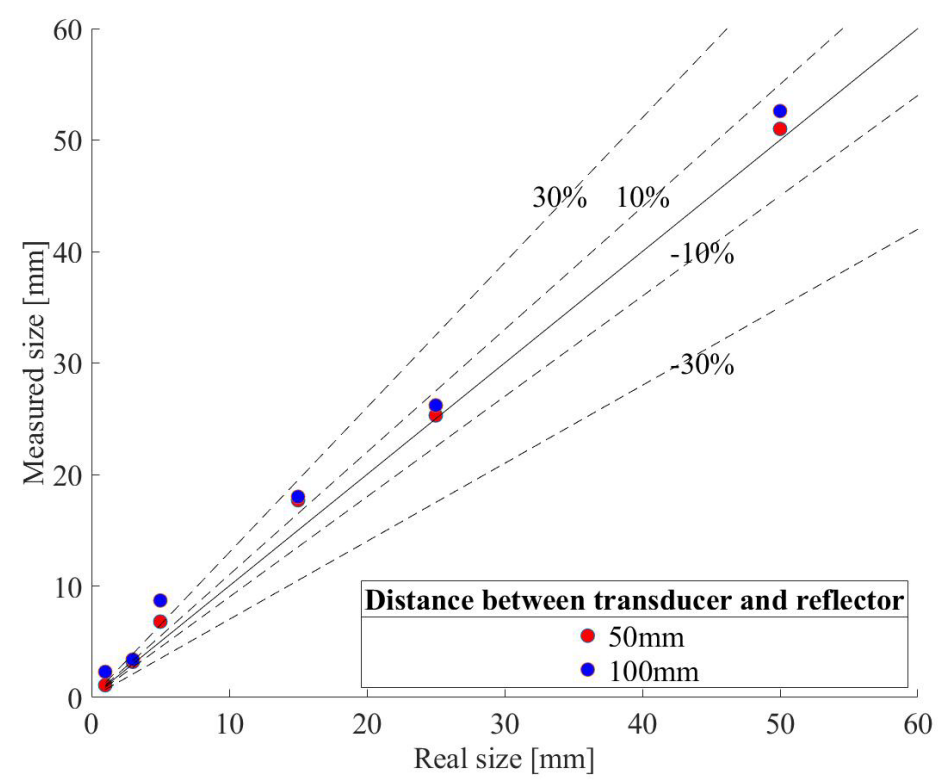

Figure 12. Measurement results of six different size of rectangles at different axial distances.

sectorial array sensor is moved along $\mathrm{x}$-direction with $3 \mathrm{~mm}$ steps by $3 \mathrm{D}$ stage to obtain whole image. Measurement performed at 24 positions along $\mathrm{x}$-axis. Total scanned area is $72 \mathrm{~mm}(24 \times 3 \mathrm{~mm})$. The measurement parameters were same as data illustrated in Table 1. The distance between bottom wall of tank and sensor surface was around $100 \mathrm{~mm}$ and a simulated debris was placed under sensor. The measurement results that integrated all 24 positions are depicted in Figure 13. Strong reflections were observed from the bottom wall of tank and surface of debris near sensor according to measurement result that showed in Figure 13. The spatial resolution along $\mathrm{y}, \mathrm{z}$ direction was $0.2 \mathrm{~mm}$ and $0.2 \mathrm{~mm}$, respectively, in the Figure 13. Measurement data at all measurement positions were integrated and $2 \mathrm{D}$ results along $\mathrm{ZY}, \mathrm{XZ}$ and $\mathrm{YX}$ are qualitatively compared with image of the simulated fuel debris in Figure 14. According to measurement data, the dimension of debris are approximately estimated as $80 \mathrm{~mm}, 69 \mathrm{~mm}$ and 50 $\mathrm{mm}$, along $\mathrm{Y}, \mathrm{X}$ and $\mathrm{Z}$ directions, respectively. Due to diffuse reflection on the rough surface, the parabolic hyperbola artifact was less than smooth surfaces on the measurement results. However, the artifact is observed from bottom wall of tank because of smooth and flat surface where highest reflection is occurred (see Figure 14).

\section{Shape and Flow Measurement by Sectorial Array Sensors}

To measure flow field and shape simultaneously, an A/D converter (National Instruments, USB-5133) is integrated with measurement system that used to shape measurement. A LabVIEW software is used to control ultrasonic system. A measurement system that reconstructed for flow and shape is showed in Figure 15. It consists with a couple of sectorial array sensors, a pulser and receiver 
(600C, P/R, Japan Probe), a multiplexer (MUX-128, Japan Probe), an A/D converter (National Instruments, USB-5133) and a laptop. The function of the multiplexer is to select desired channel or element of sensors as a transmitter and receiver.

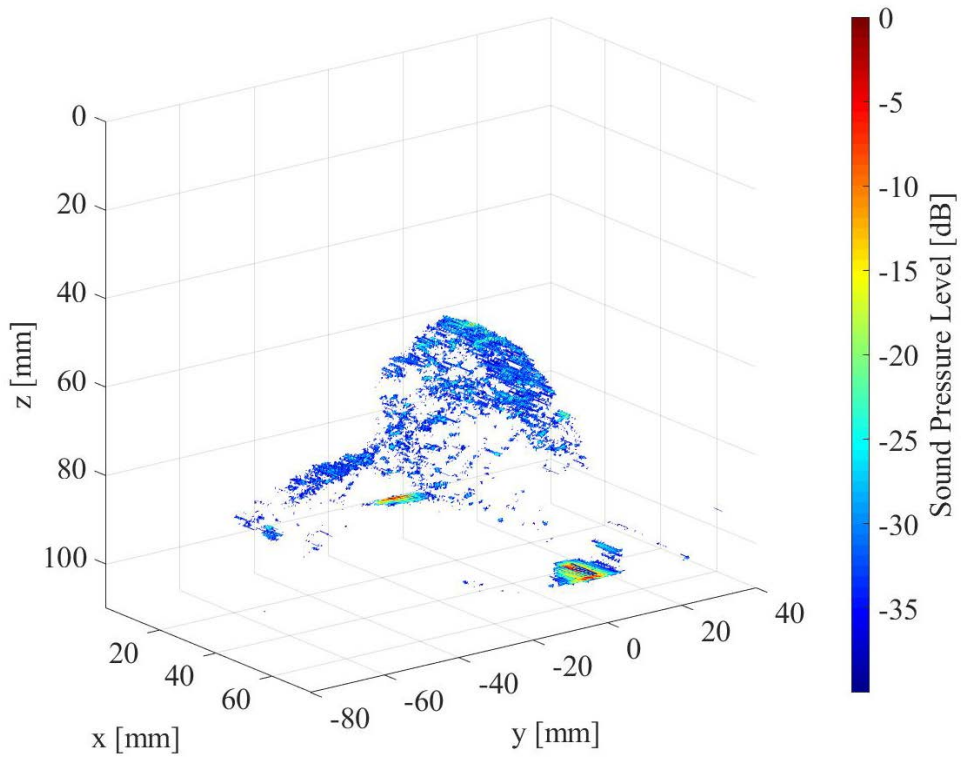

Figure 13. Measurement result of simulated fuel debris (3D views).
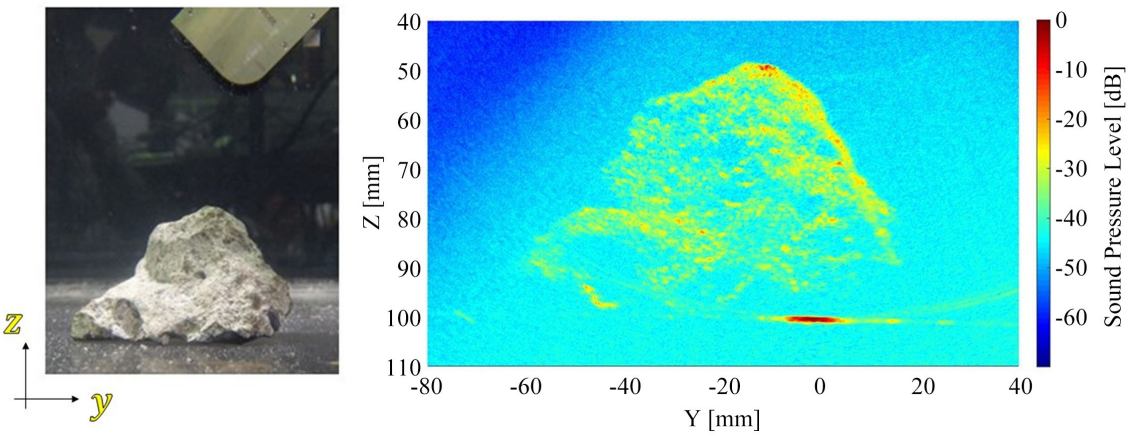

(a)
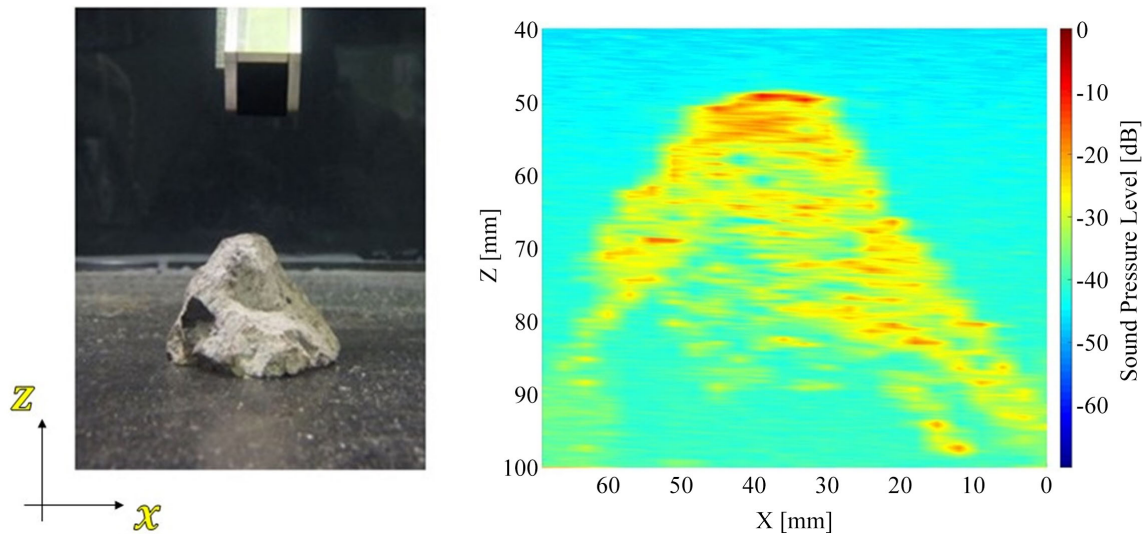

(b) 


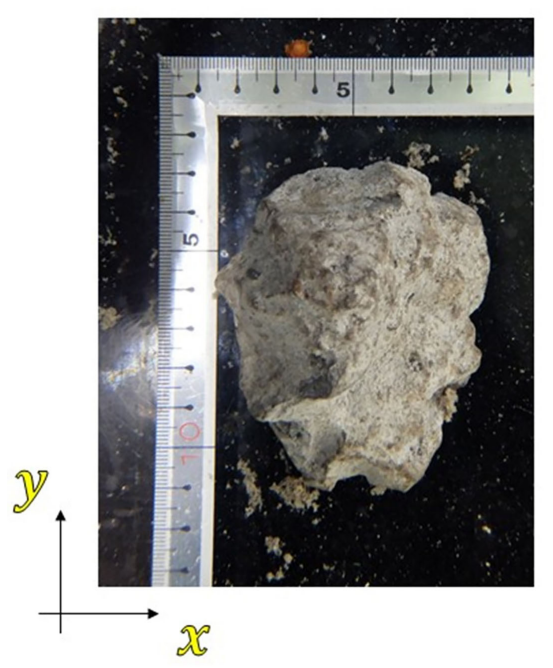

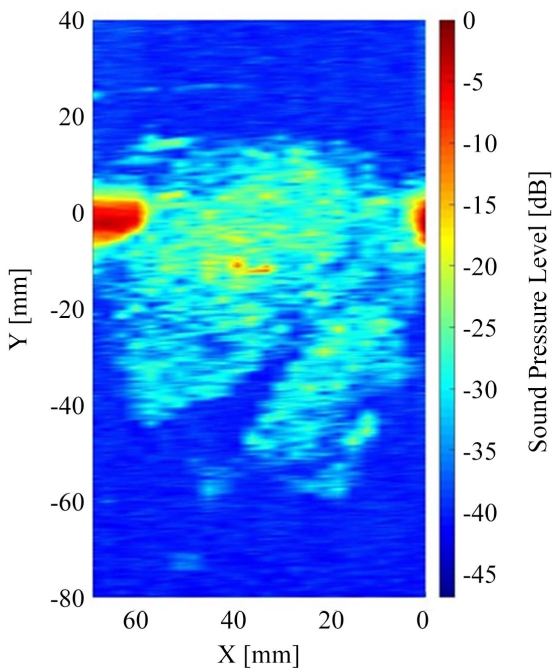

(c)

Figure 14. Measurement result of simulated fuel debris comparing with real photo of debris. (a) $z-y$ view, (b) $z-x$ view and (c) $y$-x view.

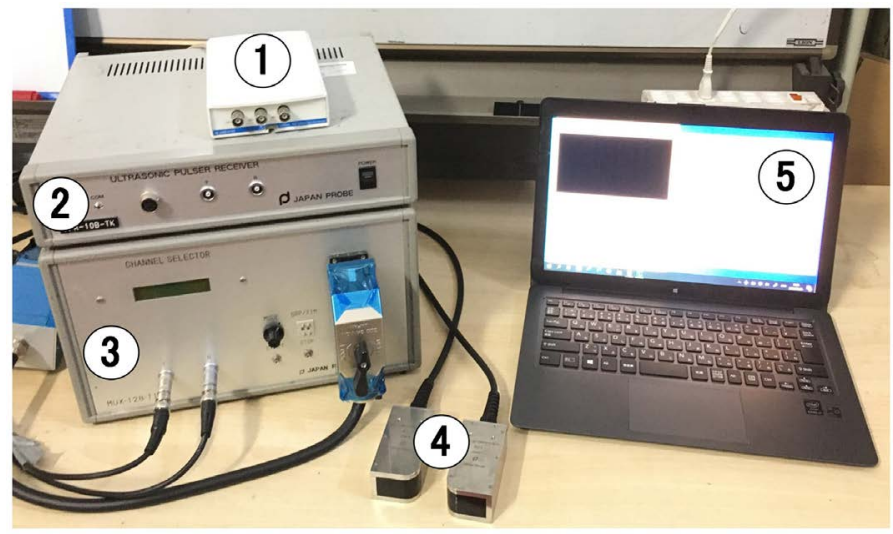

1 - A/D converter; 2 - Pulser/Receiver (P/R); 3 -Multiplexer(MUX); 4 - Sectorial array sensors; 5 - PC (LabVIEW controlling software)

Figure 15. Measurement system for flow and shape measurement.

A flow chart of measurement procedures to obtaining velocity and shape is illustrated in Figure 16. A mock-up experiment using developed system has performed in acrylic water tank with dimension of $1280 \times 450 \times 450 \mathrm{~mm}$. In this experiment, simultaneous measurement have carried out by UVP and Particle Image Velocimetry (PIV) techniques to compare measurement results of $2 \mathrm{D}$ flow field. The experimental set-up is illustrated in Figure 17. There is a drain (20 $\mathrm{mm}$ in diameter) that representing leakage point at the bottom of the tank wall. The water leakage was placed between two simulated fuel debris which has smooth and rough surfaces, respectively. Water circulated by pump (MD-100RM, Iwaki magnet pump, Iwaki Co., Ltd.) and flow rate is monitored by a flow meter (NW-10 NTN, Aichi Tokei Denki, Co., Ltd.). The flow rate in this experiment was $10 \pm 1 \mathrm{l} / \mathrm{min}$. The sectorial array sensors were located $115 \mathrm{~mm}$ above the bottom of the water tank and distance between two sensors were $90 \mathrm{~mm}$. Nylon 
series of images with $1024 \times 1024$ pixel at 500 frames per second were captured by High Speed Camera (HSC) and recorded data were proceeded further by PIVlab software in MATLAB [22]. However, in PIV data processing, only area of $410 \times 860$ pixel where main flow recorded were processed. In ultrasonic measurement, totally, $128 \times 128$ time-domain signals were stored to reconstruct object shape by TFM method. The measurement lines of all elements are illustrated in Figure 18. In the Figure 18, the black and blue lines are representing measurement pathways and angles. To obtain leakage point by UVP, 20 elements from both sensors, totally 40 measurement lines, were used to measure velocity profiles. These measurement lines are created a mesh with 259 intersection points where $2 \mathrm{D}$ velocity vectors reconstructed. The measurement parameters and conditions of the UVP and PIV are listed in Table 2.

The simulated fuel debris were visualized by sectorial array sensors as showed in Figure 19. However, the measurement result of shape deteriorated due to high flow effect where leakage point was existing between simulated debris. Moreover, the parabolic hyperbola artifacts that caused by smooth surfaces of triangle and bottom wall of tank is appeared on measurement result.

Table 2. Measurement parameters for flow and shape.

\begin{tabular}{|c|c|c|}
\hline \multicolumn{3}{|c|}{ UVP } \\
\hline Parameters & Values & Units \\
\hline Basic frequency & $8,000,000$ & {$[\mathrm{~Hz}]$} \\
\hline Sound speed & 1451 & {$[\mathrm{~m} / \mathrm{s}]$} \\
\hline PRF & 2000 & {$[\mathrm{~Hz}]$} \\
\hline Applied voltage & 120 & {$[\mathrm{~V}]$} \\
\hline Number of cycles & 8 & {$[-]$} \\
\hline Channel distance & 0.00074 & {$[\mathrm{~m}]$} \\
\hline Channel width & 0.00072 & {$[\mathrm{~m}]$} \\
\hline Number of channels & 170 & {$[-]$} \\
\hline Measurement length & 0.14 & {$[\mathrm{~m}]$} \\
\hline Number of repetition & 128 & {$[-]$} \\
\hline Number of profiles/per elements & 100 & {$[-]$} \\
\hline Total number of profiles & 5200 & {$[-]$} \\
\hline \multicolumn{3}{|c|}{ PIV } \\
\hline Parameters & Values & Units \\
\hline Frame rate & 500 & [fps] \\
\hline Shutter speed & $1 / 1000$ & {$[s]$} \\
\hline Image resolution & $1024 \times 1024$ & [pixel] \\
\hline Frame count & 5200 & {$[-]$} \\
\hline
\end{tabular}



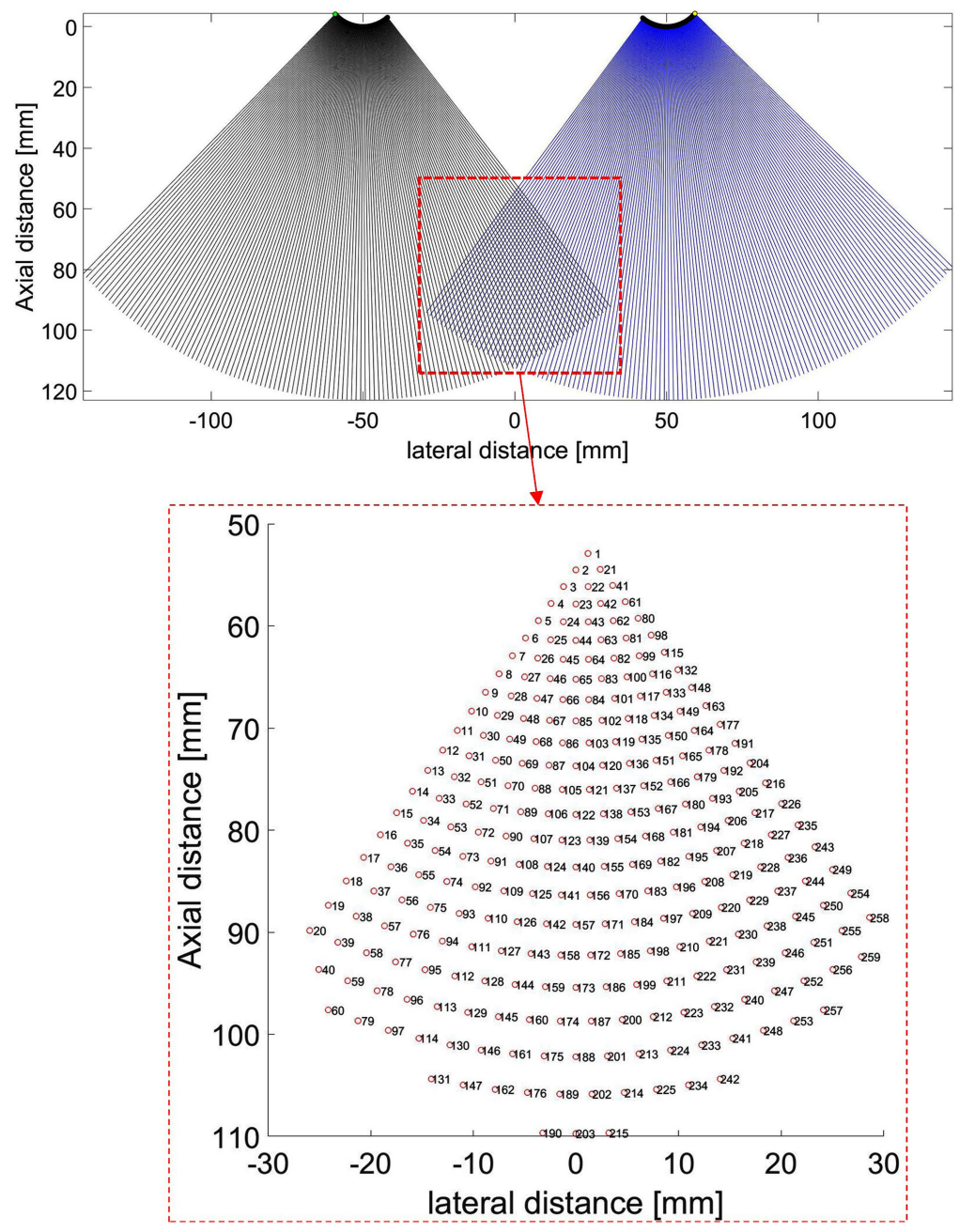

Figure 18. Illustration of measurement lines for shape and intersection points between measurement lines where $2 \mathrm{D}$ velocity vectors are constructed.

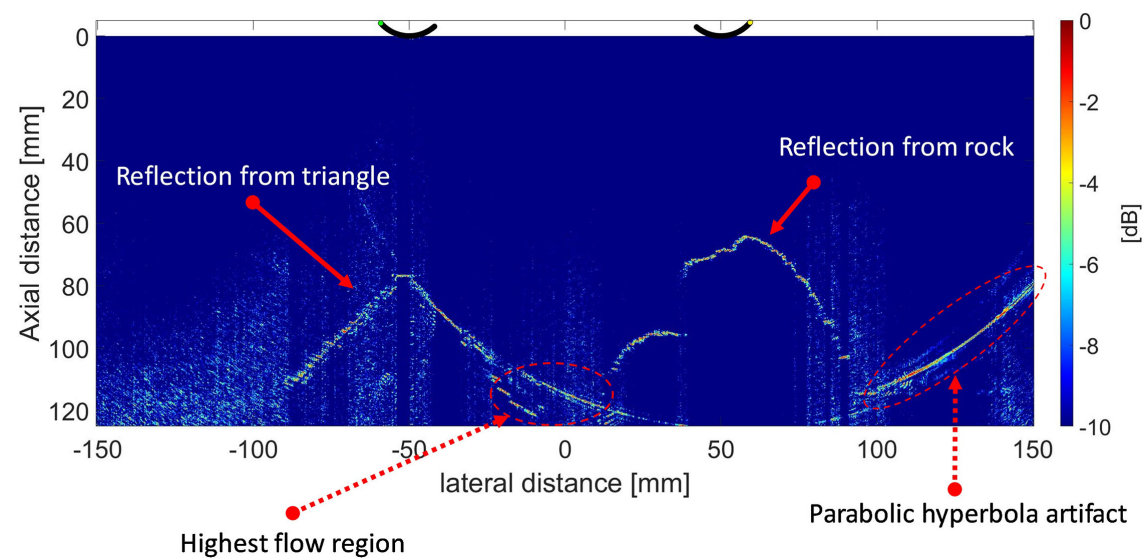

Figure 19. Measurement result of simulated fuel debris.

Measurement results of 2D velocity field by UVP and PIV are showed in Figure 20. In Figure 20(a) shows the sensors position, measurement pathways while detailed image of measurement result of UVP is showed in Figure 20(c) 
where bottom wall of the acrylic tank and simulated leakages are indicated by a solid lines (black) and empty space between lines, respectively. Figure 20(b) shows the measurement result of the PIV. 2D velocity vectors at closest coordinate are extracted from the PIV result for a qualitative comparison with UVP data and the extracted data is showed in Figure 20(d). According to qualitative comparison between UVP and PIV, highest velocity field is detected near simulated leakage point in the both results. Statistical characteristics of the UVP and PIV velocity measurements are listed in Table 3 and such statistical data interpretation were used for low flow of rivers in [23].

To demonstrate agreement between the UVP and PIV on 2D flow measurement, the Bland-Altman plot is drawn and it is showed in Figure 21(a) and

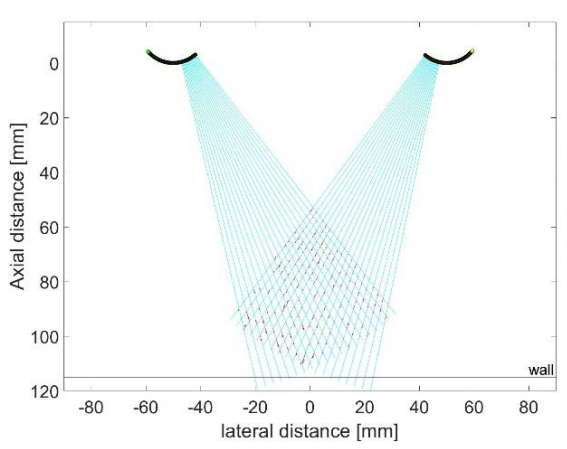

(a)

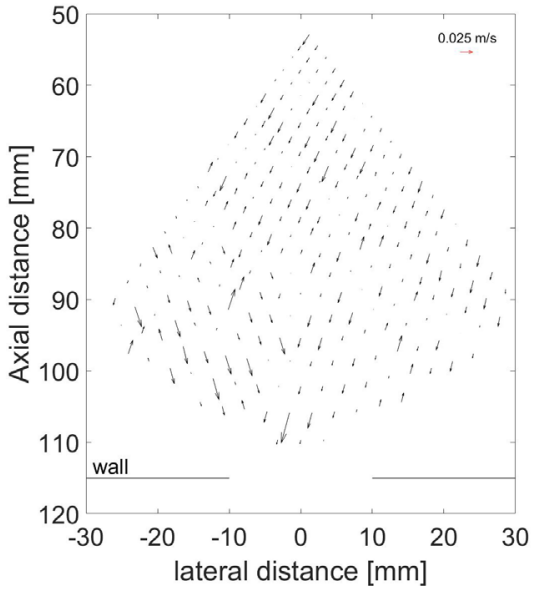

(c)

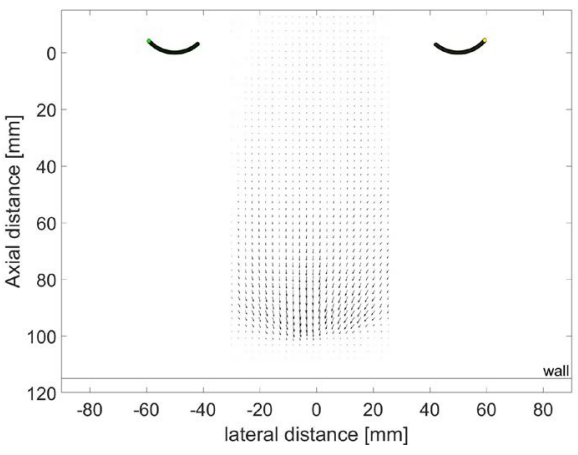

(b)

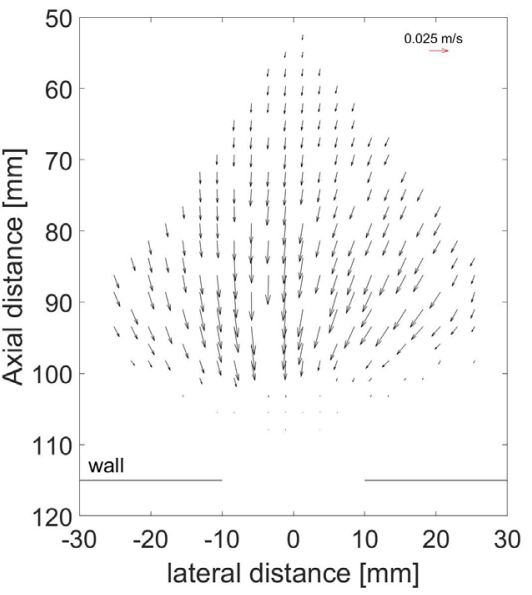

(d)

Figure 20. Measurement results of 2D vector field by UVP ((a) \& (c)) and PIV ((b) \& (d)).

Table 3. Descriptive statistics of the UVP and PIV measurements.

\begin{tabular}{ccccccc}
\hline & \multicolumn{3}{c}{$\begin{array}{c}\text { Velocity along axial } \\
\text { direction }[\mathrm{m} / \mathrm{s}]\end{array}$} & \multicolumn{3}{c}{$\begin{array}{c}\text { Velocity along lateral } \\
\text { direction [m/s] }\end{array}$} \\
\cline { 2 - 7 } & $\max$ & $\min$ & $\operatorname{mean}$ & $\max$ & $\min$ & mean \\
\hline UVP & 0.0089 & -0.0106 & $-0.8 \times 10^{-3}$ & 0.0391 & -0.0267 & 0.0042 \\
PIV & 0.0082 & -0.0159 & -0.0022 & 0.0361 & $2.8 \times 10^{-4}$ & 0.0164 \\
\hline
\end{tabular}


Figure 23(a). The Bland-Altman plot is formed by plotting the differences on vertical axis versus the averages on the horizontal axis. A red horizontal lines are representing the bias. Additional horizontal lines, known as limits of agreement (LOA), are added to the plot at $\pm 1.96 \mathrm{SD}$. According to Bland-Altman plots, most of velocity values along vertical (Figure 21(a)) and axial directions (Figure 23 (a)) are existing $\pm 1.96 \mathrm{SD}$ of the mean differences. To show outliers, in addition, distribution plots of difference between two measurement techniques are illustrated along lateral and axial direction, respectively, in the Figure 21(a) and Figure 23(a). In these histograms, for each bin, we counted the number of velocity values that fall in interval of $0.002 \mathrm{~m} / \mathrm{s}$ and $0.005 \mathrm{~m} / \mathrm{s}$ along vertical and horizontal axis, respectively. The vertical axis shows the relative frequency which is defined by ratio between absolute frequency of velocity values at each intervals and total number of data. In Figure 21(b) and Figure 23(b), outliers that existing outside of $\pm 1.96 \mathrm{SD}$ in the histograms are indicated by red (outliers higher than $\pm 1.96 \mathrm{SD}$ ) and blue (outliers lower than $\pm 1.96 \mathrm{SD}$ ) dots in the measurement grid of UVP. The most of the outliers are estimated as reverse vectors at near leakage and simulated fuel debris where high and complex flow presents. In Figure 22 and Figure 24, time averaged velocity profiles that obtained by measurement lines No.14 and No.6 of Sensor-1 and measurement lines No.5 and No.13 of Sensor-2 are illustrated because most of outliers are existing along these measurement lines. These measurement lines are indicated in the Figure 21(b) and Figure 23(b) as a black and red lines. The outliers were estimated at distance of over than $70 \mathrm{~mm}$ from sensors surface where the velocity profiles were significantly fluctuating and deteriorates as showed in Figure 22 and Figure 24. If we take a look at the SPL measurement result (Figure 8 and Figure 9), the SPL and FWHM were less than $-13 \mathrm{~dB}$ and over than 13 , respectively, after 70 $\mathrm{mm}$ from sensor surface. Eventually, an integrated measurement results of simulated fuel debris shape and $2 \mathrm{D}$ vector field by developed ultrasonic system is illustrated in Figure 25.
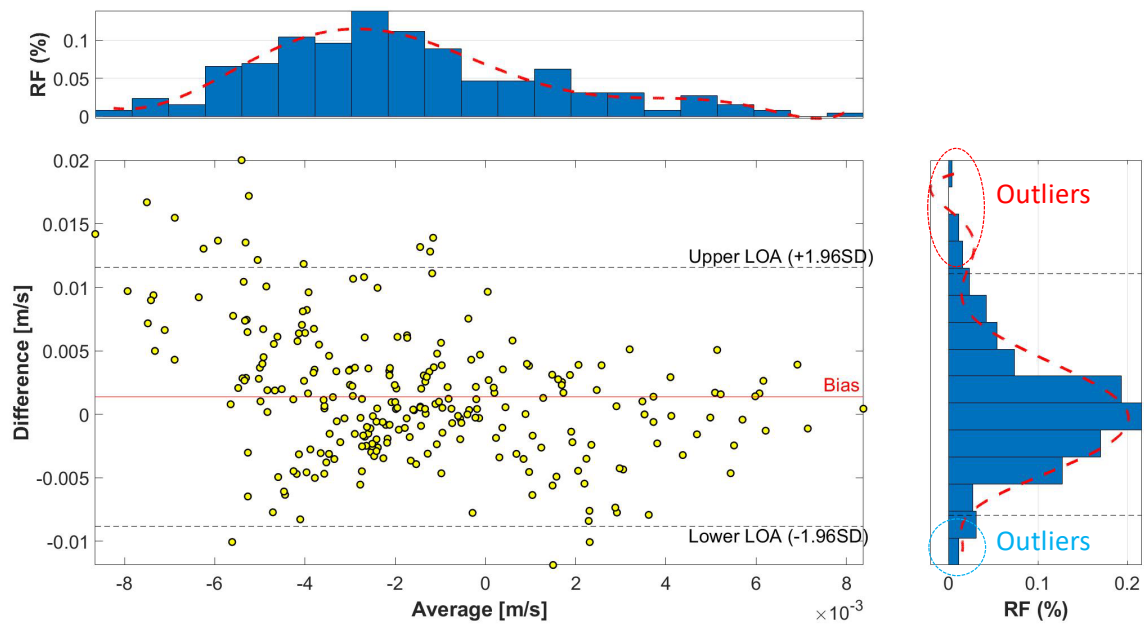

(a) 


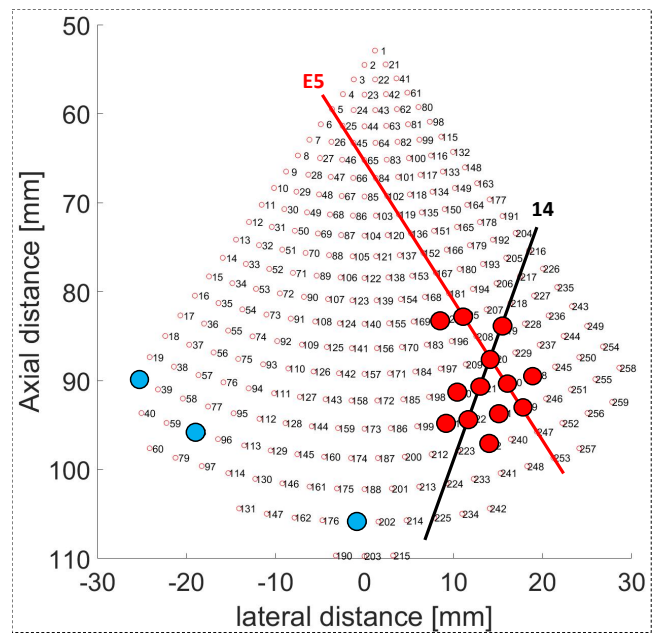

(b)

Figure 21. Agreement between the UVP and PIV velocity measurement results. (a) Bland-Altman plot of the UVP and PIV measurement results on lateral direction. (b) Outliers indicated at measurement grid of the UVP.

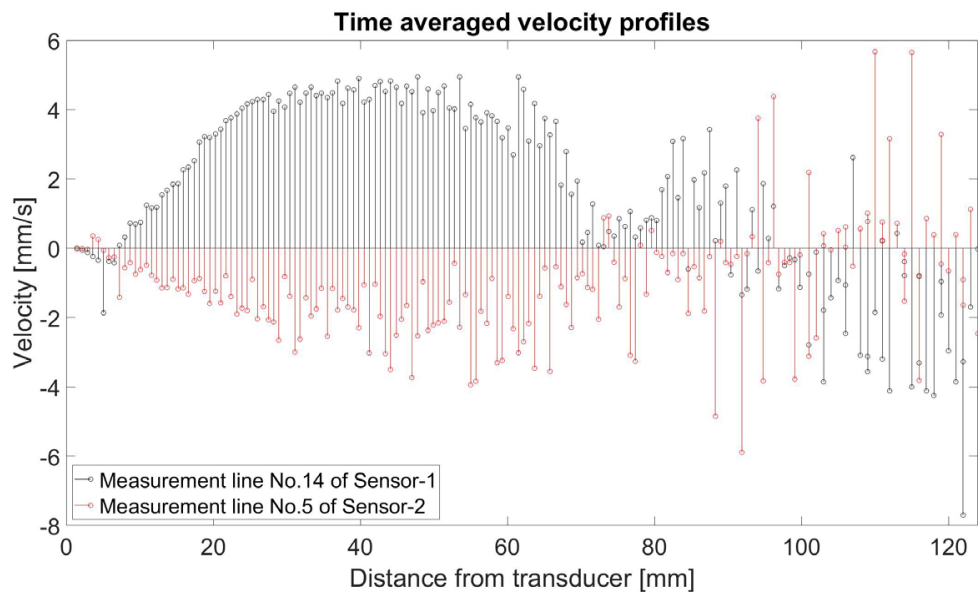

Figure 22. Time averaged velocity profiles measured by element No. 14 (black) and Element No.5 (red) of Sensor-1 and Sensor-2, respectively.
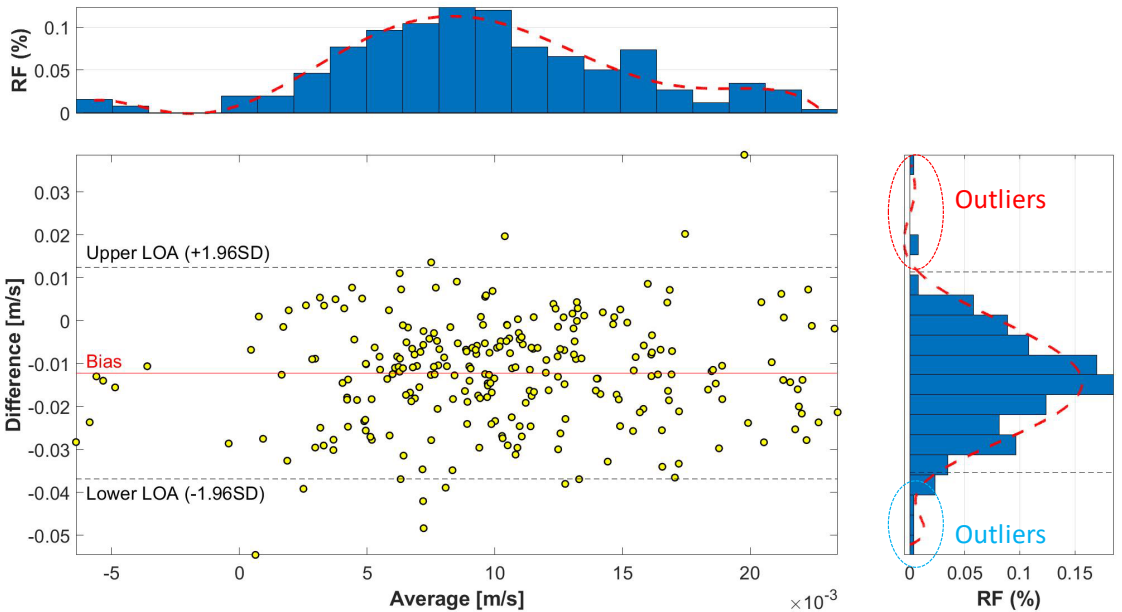

(a) 


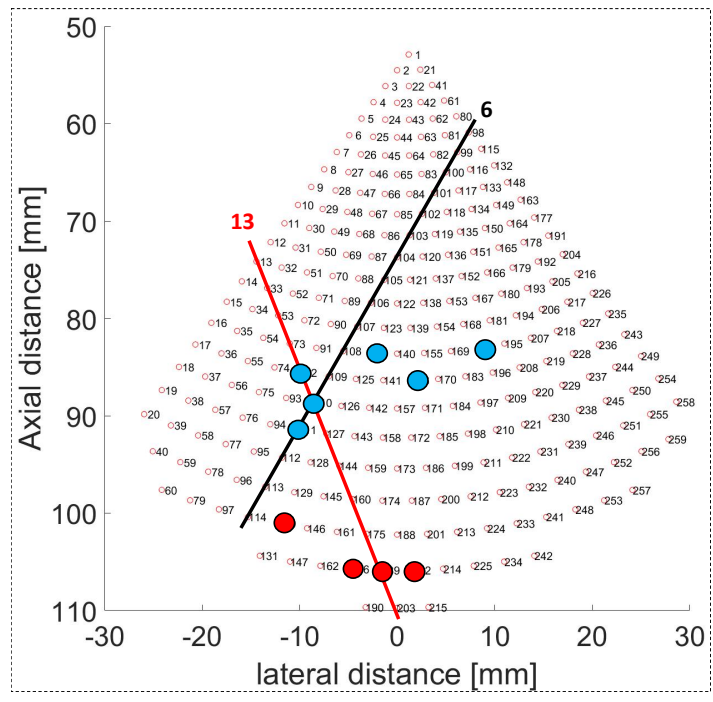

(b)

Figure 23. Agreement between the UVP and PIV velocity measurement results. (a) Bland-Altman plot of UVP and PIV measurement results on axial direction. (b) Outliers indicated at measurement grid of the UVP.

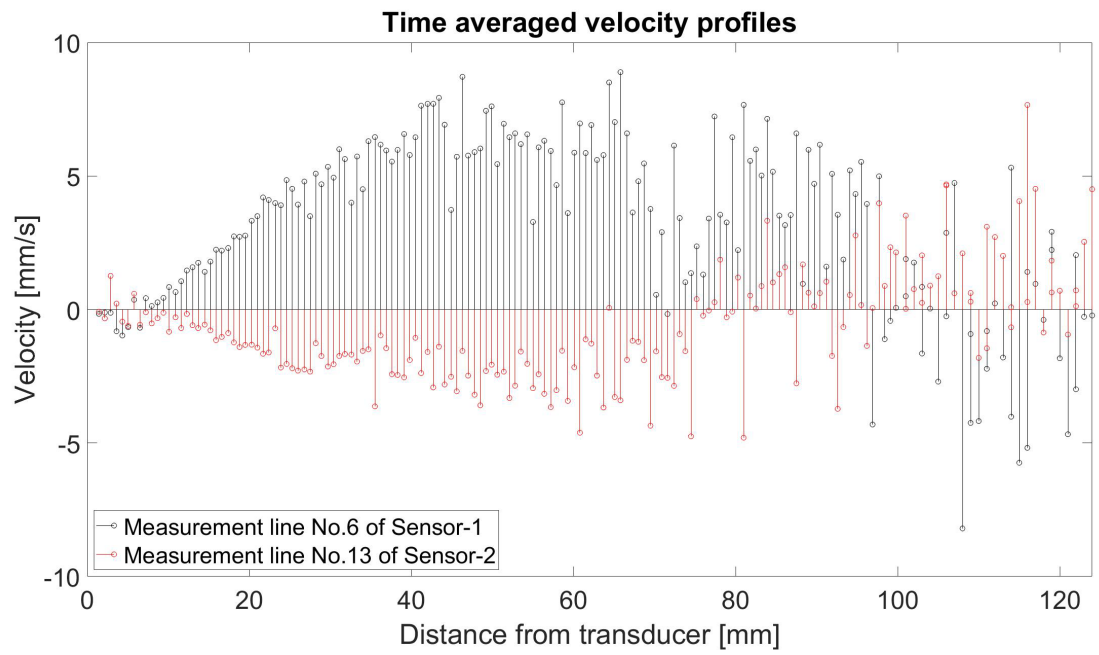

Figure 24. Time averaged velocity profiles measured by element No.6 (black) and Element No. 13 (red) of Sensor-1 and Sensor-2, respectively.

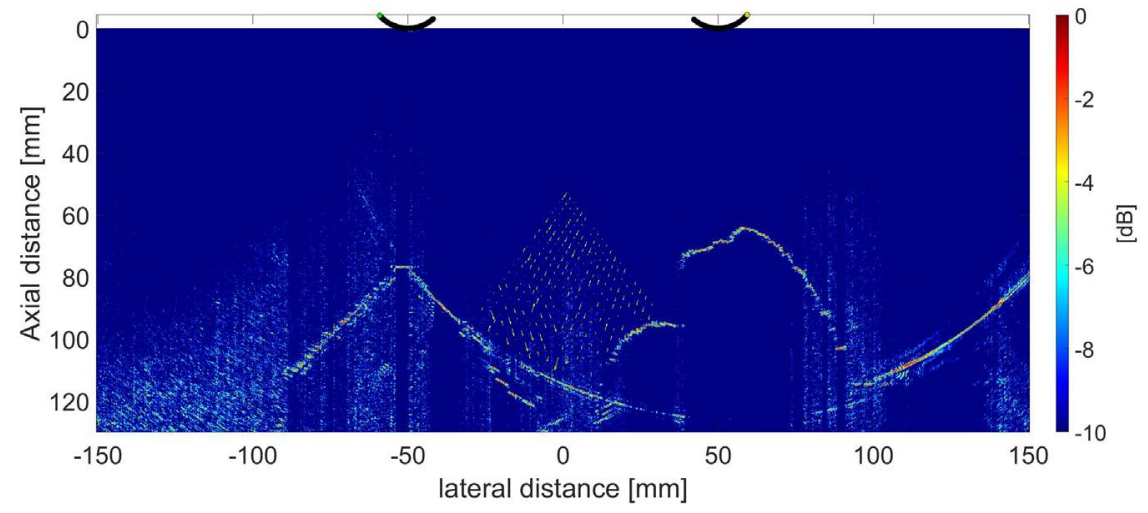

(a) 


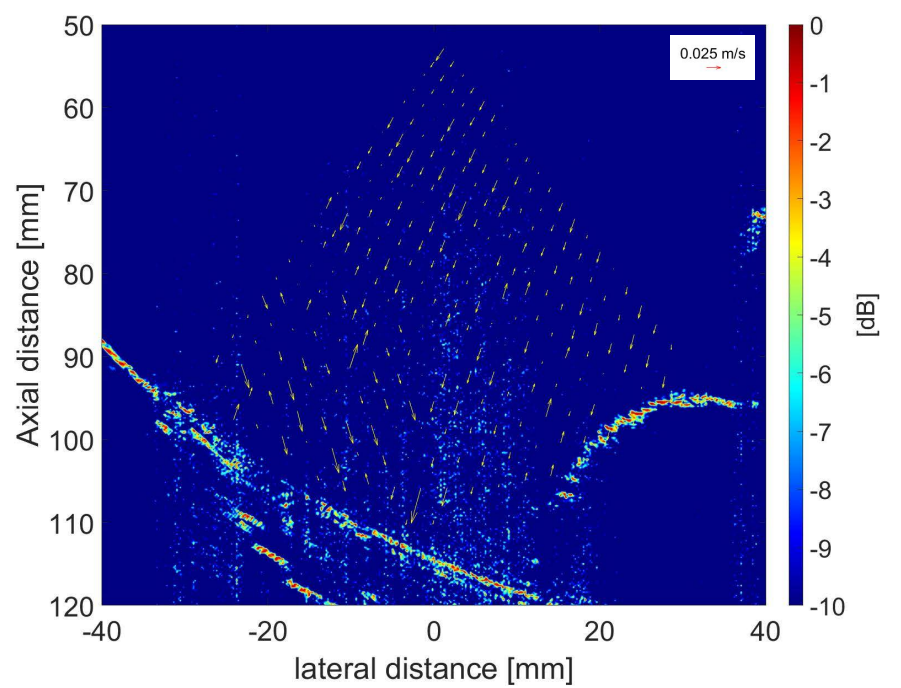

(b)

Figure 25. Integrated measurement results of simulated fuel debris and leakage point.

\section{Conclusions}

In the present study, ultrasonic measurement technique has considered as a candidate method that can obtain simultaneous information of fuel debris and contaminated water leakage from PCV of FDNPP. Therefore, a measurement system using a couple of sectorial shaped ultrasonic array sensors have developed because sectorial array sensors have some advantages, such as inspection area is larger than linear array sensor and it does not required to precise controlling of time delay for beam steering like phased array sensors. The aim of present study was to demonstrate applicability of ultrasonic measurement system for simultaneous measurement of objects and flow around it using TFM and UVP methods, respectively. The performance of the system on shape and velocity measurement have evaluated individually. After that a simultaneous measurement of shape and velocity have conducted in laboratory scaled tank where simulated debris and leakage are presented. In order to compare and validate velocity measurement results of the ultrasonic system, a simultaneous measurement by PIV technique have conducted. Main findings of present study are summarized as below.

1) Different size of simple rectangle objects were measured to assess performance of system with sectorial array sensor. Surface of the rectangle objects are successfully visualized although parabolic hyperbola artifacts appeared on the measurement results. The measurement result was showing that strong and multiple artifacts when distance between sensor and objects are short. The rectangle objects with size of $25 \mathrm{~mm}$ and $50 \mathrm{~mm}$ are measured at high accuracy with less than $10 \%$ while the smaller size of objects $(1 \mathrm{~mm}, 3 \mathrm{~mm}$ and $5 \mathrm{~mm}$ ) can be measured with around $30 \%$ of error.

2) An irregular rock sample was measured after simple rectangle objects. The dimension of the sample was length of $80 \mathrm{~mm}(\mathrm{Y})$, width of $70 \mathrm{~mm}(\mathrm{X})$ and height of $50 \mathrm{~mm}(\mathrm{Z})$. A qualitative comparison between the ultrasonic mea- 
surement and photo images of object were showed a good agreement. Dimension of the object that measured by ultrasonic revealed as length of $80 \mathrm{~mm}(\mathrm{Y})$, width of $69 \mathrm{~mm}(\mathrm{X})$ and height of $50 \mathrm{~mm}(\mathrm{Z})$.

3) A mock-up experiment have carried out in the laboratory scaled tank where simulated fuel debris and leakage are placed. Although visualization result of simulated debris by ultrasonic method was deteriorated where high flow detected, the measurement results revealed that the UVP and the TFM methods using sectorial array sensors can be visualize the shape of simulated debris and localize the water leakage point, simultaneously. To conclude, it is clarified that the measurement system with sectorial array sensors is an effective way to obtain object shape and flow around it.

\section{Acknowledgements}

The authors are grateful for the support of Ministry of Education, Culture, Sports, Science and Technology (MEXT).

\section{Conflicts of Interest}

The authors declare no conflicts of interest regarding the publication of this paper.

\section{References}

[1] Inter-Ministerial Council for Contaminated Water and Decommissioning Issues (2019) Mid-and-Long-Term Roadmap towards the Decommissioning of Fukushima Daiichi Nuclear Power Station.

[2] (2019) Technical Strategic Plan 2019 for the Decommissioning of the Fukushima Daiichi Nuclear Power Station of Tokyo Electric Power Company Holdings, Inc. https://www.dd.ndf.go.jp/files/user/pdf/en/strategic-plan/book/20191101 SP2019eF T.pdf

[3] Kikura, H., Kawachi, T. and Ihara, T. (2015) Study on Ultrasonic Measurement for Determination of Leakage from Reactor Vessel and Debris Inspection. The 11 th $\mathrm{In}$ ternational Conference on Nuclear Science and Technology. https://inis.iaea.org/search/search.aspx?orig q=RN:47065278

[4] (2015) The Fukushima Daiichi Nuclear Accident: Final Report of the AESJ Investigation Committee. Springer, Berlin. https://www.springer.com/gp/book/9784431551591

[5] Tokyo Electric Company Inc. (2015) Development of a Technology to Investigation inside the Reactor Primary Containment Vessel (PCV)-Result of Site Test "Investigation B1" on Grating around the Pedestal inside Unit 1 PCV. https://www.tepco.co.jp/en/decommision/planaction/pcv/index-e.html

[6] Tokyo Electric Company Inc. (2017) Unit 2 Primary Containment Vessel Investigation at Fukushima Daiichi Nuclear Power Plant Station (By the Self-Propelled Investigation Device).

https://www.tepco.co.jp/en/nu/fukushima-np/handouts/2018/images/handouts 180 119 01-e.pdf

[7] Outline of Decommissioning and Contaminated Water Management. Secretariat of the Team for Decommissioning and Contaminated Water Treatment. 
https://www.meti.go.jp/english/earthquake/nuclear/decommissioning/pdf/mp20200 3.pdf

[8] Kamada, S., Kato, N.K., et al. (2018) Development of ROV System to Explore Fuel Debris in the Fukushima Daiichi Nuclear Power Plant. Progress in Nuclear Science and Technology, 6, 199-202. https://doi.org/10.15669/pnst.6.199

[9] Suzuki, K. and Wawabata, K. (2020) Development of a Simulator for Underwater Reconnaissance Tasks by Utilizing Remotely Operated Robots. Proceeding of the 2020 IEEE/SICE International Symposium on System Integration, Honolulu, 12-15 January 2020. https://doi.org/10.1109/SII46433.2020.9026281

[10] Tsitsimpelis, I., Taylor, C.J. and Lennox, B. (2019) A Review of Ground-Based Robotic Systems for the Characterization of Nuclear Environments. Progress in Nuclear Energy, 111, 109-124. https://doi.org/10.1016/j.pnucene.2018.10.023

[11] Beller, L.S. and Brown, H.L. (1984) Design and Operation of the Core Tomography Data Acquisition System for TMI-2. EG\&G Idaho, Inc., Idoha Falls. https://doi.org/10.2172/6837047

[12] Constantinescu, G. and Squires, K. (2004) Numerical Investigations of Flow over a Sphere in the Subcritical and Supercritical Regimes. Physics of Fluids, 16, 14491466. https://doi.org/10.1063/1.1688325

[13] Takeda, Y. (1995) Velocity Profile Measurement by Ultrasonic Doppler Method. Experimental Thermal and Fluid Science, 10, 444-453. https://doi.org/10.1016/0894-1777(94)00124-Q

[14] Kasai, C., Namekawa, K., Koyano, A., et al. (1985) Real-Time Two-Dimensional Blood Flow Imaging Using an Autocorrelation Technique. IEEE Transactions on Sonics and Ultrasonics, SU-32, 458-463. https://doi.org/10.1109/T-SU.1985.31615 http://bme.elektro.dtu.dk/31545/documents/kasai et al 1985.pdf

[15] Lemmin, U. and Rolland, T. (1997) Acoustic Velocity Profiler for Laboratory and Field Studies. Journal of Hydraulic Engineering, 123, 1089-1097. https://doi.org/10.1061/(ASCE)0733-9429(1997)123:12(1089)

[16] Dunmire, B., Beach, K.W., Labs, K.-H., et al. (2000) Cross-Beam Vector Doppler Ultrasound for Angle-Independent Velocity Measurements. Ultrasound in Medicine \& Biology, 26, 1213-1235. https://doi.org/10.1016/S0301-5629(00)00287-8

[17] Andreev, O., Kolenski, Y. and Thess, A. (2009) Application of the Ultrasonic Velocity Profile Method to the Mapping of Liquid Metal Flows under the Influence of a Non-Uniform Magnetic Field. Experiments in Fluids, 46, 77-83. https://doi.org/10.1007/s00348-008-0540-2

[18] Takeda, Y. and Kikura, H. (2002) Flow Mapping of the Mercury Flow. Experiments in Fluids, 32, 161-169. https://doi.org/10.1007/s003480100296

[19] Munkhbat, B., Hamdani, A. and Kikura, H. (2018) Velocity Measurement on TwoPhase Air Bubble Column Flow Using Array Ultrasonic Velocity Profiler. International Journal of Computational Methods and Experimental Measurements, 6, 86-97. https://doi.org/10.2495/CMEM-V6-N1-86-97

[20] Munkhbat, B., Hamdani, A. and Kikura, H. (2017) Visualization of Air-Water Bubbly Column Flow Using Array Ultrasonic Velocity Profiler. Theoretical and Applied Mechanics Letters, 7, 379-385. https://doi.org/10.1016/j.taml.2017.09.014

[21] Holmes, C., Drinkwater, B. and Wilkox, P.D. (2005) Post Processing of the Full Matrix of Ultrasonic Transmit-Receive Array Data for Non-Destructive Evaluation. NDT\&E International, 38, 701-711. https://doi.org/10.1016/j.ndteint.2005.04.002

[22] Thielicke, W. and Stamhuis, E.J. (2014) PIVlab-Towards User-Friendly, Afforda- 
ble and Accurate Digital Particle Image Velocimetry in MATLAB. Journal of Open Research Software, 2, e30. https://doi.org/10.5334/jors.bl

[23] Eris, E., Aksoy, H., Onoz, B., et al. (2019) Frequency Analysis of Low Flows in Intermittent and Non-Intermittent Rivers from Hydrological Basins in Turkey. Water Science and Technology: Water Supply, 19, 30-39.

https://doi.org/10.2166/ws.2018.051 


\section{Nomenclature}

\begin{tabular}{|c|c|c|c|}
\hline$s[\mathrm{~m}]$ & Starting depth & $N_{\text {rep }}[-]$ & Number of repetition per profile \\
\hline$w[\mathrm{~m}]$ & Channel width & $P R F[\mathrm{~Hz}]$ & Pulse Repetition Frequency \\
\hline$W[\mathrm{~m}]$ & Length of measurement window & $N[-]$ & Number of elements in array sensor \\
\hline$h[\mathrm{~m}]$ & Channel distance & $t[\mathrm{~s}]$ & Time \\
\hline$x_{t x}[\mathrm{~m}]$ & $\begin{array}{l}\mathrm{x} \text {-coordinate of transmitting element in } \\
\text { array sensor }\end{array}$ & $A[-]$ & Time domain signal \\
\hline$x_{I X}[\mathrm{~m}]$ & $\begin{array}{l}\mathrm{x} \text {-coordinate of receiving element in } \\
\text { array sensor }\end{array}$ & $H[-]$ & Hilbert transformation of raw signal \\
\hline$y_{t x}[\mathrm{~m}]$ & $\begin{array}{l}y \text {-coordinate of transmitting element in } \\
\text { array sensor }\end{array}$ & $P[-]$ & Pixels of imaging area \\
\hline$y_{r x}[\mathrm{~m}]$ & $\begin{array}{l}y \text {-coordinate of receiving element in } \\
\text { array sensor }\end{array}$ & $D[-]$ & $\begin{array}{l}\text { Directivity function of transmitting } \\
\text { \& receiving elements }\end{array}$ \\
\hline$u_{1}[\mathrm{~m} / \mathrm{s}]$ & $\begin{array}{l}\text { Velocity component that measured by } \\
\text { sensor-1 }\end{array}$ & $a[\mathrm{~m}]$ & Element width \\
\hline$\iota_{2}[\mathrm{~m} / \mathrm{s}]$ & $\begin{array}{l}\text { Velocity component that measured by } \\
\text { sensor-2 }\end{array}$ & $\lambda[\mathrm{m}]$ & Wavelength \\
\hline$d_{1}[\mathrm{~m}]$ & $\begin{array}{l}\text { Distance from sensor to intersection } \\
\text { point in sensor } 1\end{array}$ & $b[\mathrm{~m}]$ & Element height \\
\hline$d_{2}[\mathrm{~m}]$ & $\begin{array}{l}\text { Distance from sensor to intersection } \\
\text { point in sensor } 2\end{array}$ & $c[\mathrm{~m}]$ & Inter-element spacing \\
\hline$\theta[\mathrm{deg}]$ & Azimuth angle & $R[\mathrm{~m}]$ & Curvature \\
\hline$C h[-]$ & Intersecting channel number & $I[-]$ & Sound pressure \\
\hline$V[-]$ & Velocity value along $\mathrm{x}$ and $\mathrm{y}$ direction & $\Delta t[\mathrm{~s}]$ & Time resolution \\
\hline$\Delta x[\mathrm{~m}]$ & Spatial resolution & $R f[-]$ & Autocorrelation function \\
\hline$I(t)[-]$ & In phase signal & $Q(t)[-]$ & Quadrature signal \\
\hline$z(t)[-]$ & Envelope signal & $\varphi[-]$ & Phase shift between echo signals \\
\hline
\end{tabular}

\section{Subscripts}

$i, j \quad$ Transmitting and Receiving elements 2D Two-dimension

\section{Abbreviations}

FDNPP Fukushima Daiichi Nuclear Power Plant UVP

PCV Primary Containment Vessel

RPV Reactor Pressure Vessel

TMI Three Mile Island

SPL Sound Pressure Level

MUX Multiplexer

PIV Particle Image Velocimetry

SD Standard Deviation

RF Relative Frequency
TFM

TX Sensor

Ultrasonic Velocity Profiler

Total Focusing Method

PRF Pulse Repetition Frequency

PR Pulse Repetition

FWHM Full Width at Half Maximum

LOA Limit Of Agreement

sinc sine cardinal 